\title{
LOS MOROS DE NAVAL (NABAL) EN LOS SIGLOS XV Y XVI
}

\author{
THE NAVAL'S MUDEJAR COMMUNITY IN THE $15^{\text {th }}$ AND $16^{\text {th }}$ CENTURIES
}

Ánchel Conte Cazcarro

Catedrático jubilado de Enseñanza Media

Resumen: En la pequeña villa de Naval se localiza la más septentrional de las comunidades mudéjares de Aragón que, aun sin ser muy numerosa, ha dado abundante documentación desigual en el tiempo, pero que ha permitido hacer una aproximación a su población y a sus actividades económicas a lo largo del siglo XV y comienzos del siglo XVI. Las aproximadamente treinta familias que la integraban, alrededor del 50\% del total de la población, queda probado que participaron en la producción de sal, la principal riqueza del pueblo, en la agricultura y, sobre todo, en el comercio. A pesar de ser una villa rica por la producción de sal y los beneficios que reportaba el comercio, cristianos, judíos y moros se vieron obligados con frecuencia a endeudarse colectivamente con la venta de censales que suponían una fuerte carga económica.

Palabras clave: Mudéjares, Aragón, Huesca, Naval, sociedad, economía.

\begin{abstract}
In the small village of Naval is located the most northern of Mudejar communities of Aragon, while not very large, has extensive documentation uneven over time, but that has permitted an approach to its population and its economic activities to throughout the Fifteenth Century and early Sixteenth Century. The approximately thirty families that were involved, about $50 \%$ of the total population is proved that participated in the production of salt, the main wealth of the people in agriculture and especially in trade. Although it is a town rich in salt production and trade positive benefits, Christians, Jews and Moors were often forced into debt by selling collectively census which involved heavy economic.
\end{abstract}

Keywords: Mudejar, Aragon, Huesca, Naval, society, economy. 


\section{LAS FUENTES}

Todas la fuentes utilizadas para este trabajo son inéditas, y consisten en protocolos notariales de Barbastro, conservados en el Archivo Histórico Provincial de Huesca (AHPH), protocolos notariales y otros fondos del Archivo Municipal de Barbastro (AMB), y un protocolo notarial de Aínsa, también en el AHPH. Hay, además, un protocolo del Archivo de la Corona de Aragón (ACA), un documento del Archivo Diocesano de Barbastro (ADB) del siglo XVII, y uno de la casa ducal de Híjar del Archivo Histórico Provincial de Zaragoza (AHPZ).

Sobre la villa ${ }^{1}$ se cuenta con abundante documentación real que ha sido dada a conocer por numerosos historiadores que la han estudiado, y cuya obra queda recogida en la bibliografía final. Van desde las capitulaciones entre Pedro I y los moros navaleses ${ }^{2}$ a monografías recientes en las que se recapitula una parte de la vasta documentación de la Cancillería Real del ACA y otras fuentes recogida en los distintos estudios realizados hasta la actualidad, y aunque las noticias sobre los moros son pocas y muchas veces indirectas, se hará referencia a ellas en el momento oportuno. Mención especial merece el trabajo de Privato Cajal Sazatornil, que hace un estudio exhaustivo de la documentación del ACA referente a Naval, centrado básicamente en los registros de Cancillería y menos en otras secciones, especialmente de los siglos XIII y XIV, dejando una enorme laguna en el siglo XV, acaso porque ya la villa no era de realengo y generó menos documentación en la Cancillería Real ${ }^{3}$.

Los problemas que plantean las fuentes trabajadas para el trabajo que presento es que la práctica totalidad de los documentos, excepto los referentes a los plenarios del concejo o de la aljama, están hechos fuera de Naval y que apenas proporcionan leves pinceladas de lo que pudo ser la vida cotidiana del colectivo, ya que las escrituras propias de la aljama, así como de sus individuos, pero que sólo afectan a los moros, están casi ausentes, y cuando aparecen, salvo algún caso excepcional, se refieren a operaciones de carácter económico sometidas a Fuero. Es claro y evidente que la aljama tuvo sus propios notarios, como luego se expondrá, y que instrumentos clave para entender

1.- El topónimo, atendiendo a su forma medieval (Napal), debería ser Nabal.

2.- Ricardo Del Arco y Garay: "De la Edad Media en el Alto Aragón: I. Documentos de Alquézar. II. Privilegio de ingenuidad y franquicias de la villa de Naval. III. Cuaderno de Privilegios reales de la villa de Sariñena. IV. Ordinaciones reales de Barbastro (1454)", Estudios de la Edad Media de la Corona de Aragón, II, (1946), pp. 433-468.

Antonio Durán Gudiol: Colección Diplomática de la catedral de Huesca, vol. I, Zaragoza, Escuela de Estudios Medievales, documento 76, p. 104.

3.- Privato Cajal Sazatornil: X siglos de historia de Naval (Huesca) y sus salinas y anecdotario del autor, Barcelona, edición del autor, 1969. 
el rumbo de la aljama, como testamentos, capitulaciones matrimoniales, actas del plenario, es decir, casi todos aquellos documentos que nos permitirían reconstruir con precisión la vida del colectivo, habrían sido realizados ante notario muslim y se han perdido en su totalidad. A esto hay que añadir un problema tan serio como es la falta de información de los primeros y últimos años del siglo XV, y de comienzos del XVI, concentrándose casi todos los datos en muy pocos años, especialmente en la década de 1470 y más aún en la de 1480 y concretamente en el año 1485, sin que haya una explicación a este fenómeno a no ser el hecho de que creciera la actividad económica de la villa tras la renovación por Fernando el Católico de los privilegios que disfrutaba para comercializar su sal en un vasto territorio que abarca la casi totalidad de la actual provincia de Huesca (1481).

Podría pensarse, al ver el resultado, que la pobreza de información en la primera mitad del siglo XV y en los últimos años de esa centuria se debe a la pérdida de fuentes, pero no es así; es cierto que son más escasas, pero no hasta el extremo de que ese sea el motivo que justifique el vacío de noticias que hay sobre los moros de Naval. El hecho es que, sencillamente, no hay escrituras en las que aparezcan, a pesar de que cuesta creer que su comportamiento fuera muy distinto al del momento en que generan el grueso de la documentación conocida. A pesar de estas limitaciones, estamos ante un buen conjunto de documentos notariales que, al menos, nos van a permitir acercarnos a este colectivo del que mucho se ha hablado, poco se ha estudiado y, menos aún, publicado. La villa de Naval, de población mixta, como se verá, tenía la comunidad musulmana más septentrional de Aragón. Vamos a poder proporcionar una visión aproximada de su realidad socioeconómica, aunque desigual en el tiempo. No obstante, entendemos que, tanto desde el punto de vista organizativo como económico, esta podría ser, más o menos válida para toda la historia de la comunidad hasta su obligado bautismo.

\section{BREVE INTRODUCCIÓN HISTÓRICA}

La referencia bibliográfica más interesante es el reciente estudio de Juan Miguel Rodríguez Gómez ${ }^{4}$ sobre los arrieros en Aragón y su relación con

4.- Joaquín Rodríguez Gómez: "La sal y el origen de la arriería (II): Naval, centro salinero del Alto Aragón (I)", Revista Serrablo, XXXVIII, 148, (junio 2008), sin paginar. Accesible en http;//www. serrablo.org/revista/148/arrieros-en-serrablo.

IDEM: "La sal y el origen de la arriería (III): Naval, centro salinero del Alto Aragón (II)", Revista Serrablo, XXXIX, 152, (junio 2009), sin paginar. Accesible en http://www.serrablo.org/revista/152/ arrieros-en-serrablo. 
la sal de Naval, que recoge los aspectos más destacados de cuantos trabajos anteriores hablaban de la villa y de la sal desde el momento de la reconquista hasta épocas modernas. Como se basa fundamentalmente en documentación real, no toca los temas que vamos a tratar en este artículo. No obstante, parece necesario incluir este breve resumen histórico que sirva de marco a la realidad de la comunidad mudéjar del siglo XV, basado fundamentalmente en las obras citadas anteriormente.

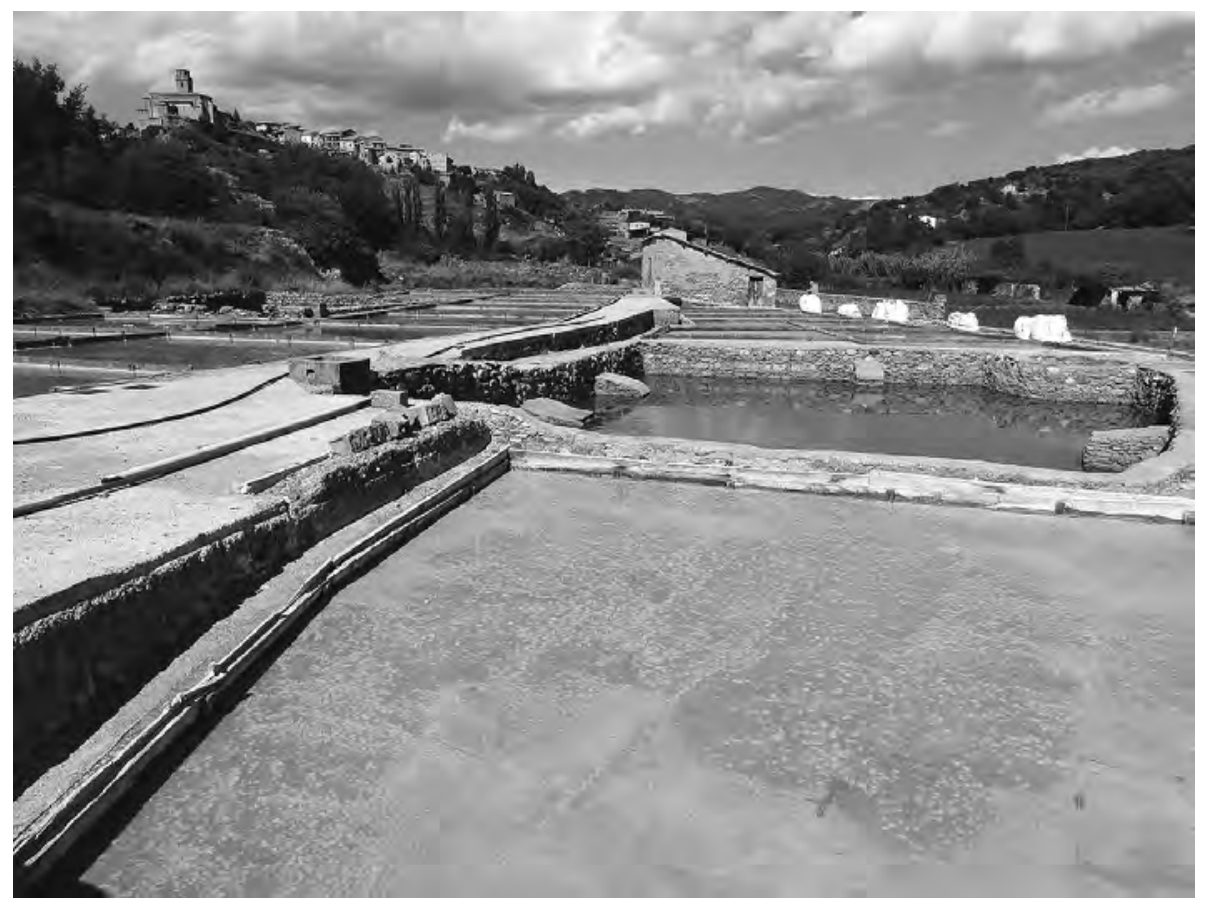

Fig. 1. Estado actual del salinar de La Rolda, que mantiene la estructura de la explotación medieval (Foto: Ánchel Conte)

La villa musulmana de Naval explotaba los salinares (figura 1) que han llegado hasta nuestros días, y desde siempre esta sal ha sido exportada dando origen a uno de los oficios característicos de la villa, el de arriero o trajinero. Cuando en 1099 se dan las capitulaciones entre la villa islámica y el rey Pedro I, se garantiza que la población musulmana que permanece en la villa, y que en ese momento suponía la casi totalidad de la misma, quedara exenta de algunos impuestos, pudiera seguir manteniendo su religión, tener mezquita y continuar con la posesión y explotación de las salinas a cambio 
de pagar el noveno de los frutos de la tierra y de ganado y el quinto de la sal, tal como vemos en Durán Gudiol:

“(...) propter servicia que mihi fecistis et me donastis illo castello de Napale, ingenuo vos de totas parias et de totas azofras quod mihi facere debebatis et quod donetis mihi de totu vestrum fructum quod colligeritis de pane et de vino et de milgo et de totos fructos quod unquam abueritis et de vestras bestias (...) illa novena ad me et de tota vestra sale quod donets mihi inde illo quinto, et quod non donetis in tota mea terra calonia (...)". [(...) por los servicios que me hicisteis y por darme el castillo de Naval, os libero de todas las parias y azofras y me deis de cuanto fruto recojáis de cereal y de vino y de mijo y de todos los frutos que siempre tendréis y de vuestro ganado (...) la novena parte y de vuestra sal me deis el quinto, y que no me deis en toda mi tierra caloña $(\ldots)]^{5}$.

En 1242, los moros pagaban 300 sueldos jaqueses ${ }^{6}$ al monasterio de Escarp por las eras salineras que explotaban, a lo que el monasterio renunció al año siguiente en beneficio del rey, y en 1242 el rey y el monasterio llegan a un acuerdo sobre la precepción del quinto de las salinas ${ }^{7}$. La entrega de eras salineras a otras instituciones religiosas y a la nobleza fue en detrimento del número de propietarios moros, pero no de los trabajadores de las mismas, porque todo parece indicar que la mayoría de los que se dedicaban a la sal seguían siendo musulmanes. De hecho, en el presente artículo se contempla el caso de unas eras treuderas al monasterio de Sijena pero en tenencia de moros como ejemplo de lo que parece que se generalizó. A lo largo de la historia, mientras la villa estuvo bajo jurisdicción real, fueron numerosas las exenciones reales que demuestran el interés de los monarcas por el lugar, así Pedro III los eximió de los servicios del ejército (1277) y Jaime II (1310) del monedaje ${ }^{8}$. Se sabe que en 1294 los moros pagaban 100 sueldos al año más 15 cahíces de cereal y el noveno de los frutos del campo, además de estar obligados a llevar leña los sábados al castillo9 . El número de explotaciones en manos de los moros debió de ser muy abundante, porque, por ejemplo, todos los que explotaban el salinar de Ryusico (Rosico) en 1366 eran musulmanes, según Cajal ${ }^{10}$. El desinterés de este autor por los moros es tan evidente que llega a considerarlos como extraños, hasta el extremo de decir comentando un documento de 1378 que "entre muchos nombres moros, vemos en esta

5.- A. Durán: Colección, p. 104.

6.- Siempre que se hable de sueldos, habrá que entender que son sueldos jaqueses.

7.- P. CAJAL: $X$ siglos, pp. 5-6

8.- Ibídem: pp. 7 y 10.

9.- Ibídem: p. 8.

10.- Ibídem: p. 12. 
relación otros del país", y a continuación enumera a varios cristianos, ignorando los nombres de los mudéjares, como si estos no fueran "del país"11.

Los monarcas tenían una buena fuente de ingresos en las salinas de Naval, concretamente, 4615 sueldos parecen ser los derechos reales, o al menos eso es lo que arrienda Violante de Hungría (1237), que tuvo en su patrimonio la villa ${ }^{12}$. Alfonso III $(1286)^{13}$ pone en arriendo la totalidad de las salinas durante dos años, y a partir de ese momento se dan situaciones complicadas entre quienes se disputaban el control de las salinas y de su producto y los habitantes de la villa, hasta el extremo de que estos deben acudir al rey en $1283^{14}$ para protestar por las dificultades que encuentran para comercializar la sal e incluso para el uso privado de la misma, a pesar del documento de Jaime I de 1274 en el que concedía a Naval el monopolio de venta de sal en un vasto territorio que abarcaba desde Monegros hasta Canfranc, desde el río Cinca medio hasta el río Gállego, desde la Sierra de Troncedo hasta Berdún, y desde Berdún a Longás, en Cinco Villas ${ }^{15}$. Es por esta época cuando se construyó el alfolí con el fin de almacenar y controlar toda la producción de sal. El privilegio del rey Jaime I fue confirmado posteriormente por Jaime II (1313), Pedro IV (1363), Fernando el Católico (1481) y Carlos I (1537) ${ }^{16}$. En 1512 la reina Germana de Foix estableció fuertes sanciones para quien introdujese o usase otra sal que no fuera de Naval en el territorio en que los navaleses tenían el estanco ${ }^{17}$. La villa permaneció en poder real hasta 1381, en que Pedro IV la vendió al barcelonés Jaime Ombau alias Pallarés, quien en 1387 se hace con ella por cesión de Juan I, incapaz de pagar los más de 118.000 sueldos que le debía ${ }^{18}$. A pesar de estar en manos de la nobleza ${ }^{19}$, los reyes siguieron legislando sobre las salinas y la comercialización de la sal, de lo que recibían beneficios económicos. Sin duda, eran conscientes de que constituía uno de los motores del mercado en el norte del reino. Cristianos, moros y judíos vivían de la sal directa o indirectamente, bien produciéndola, bien comercializándola y trasportándola por todo el territorio en que Naval tenía la exclusiva.

11.- Ibídem: p. 13.

12.- Ibídem: p. 6.

13.- Ibídem: p. 8.

14.- J.M. RodRíGUez: La sal, (II), sin paginar.

15.- P. CAJAL: $X$ siglos, p. 7.

16.- Ibídem: pp. 10, 12, 16 y 17.

17.- Ibídem: p. 17.

18.- Ibídem: pp. 13-14.

19.- En la documentación estudiada solamente aparece mencionada, en 1422, como señora de la villa Teresa de Híjar, hija de los duques de Híjar, viuda de Juan López de Gurrea, con quien casó en 1487, siendo éste señor de Naval, Berbegal, Albero, Piracés, Oitura, Novallas y Cunchillos. 


\section{Aproximación a la población mora de naVAl EN El Siglo XV}

Siempre se ha considerado a la comunidad mora de Naval importante dentro de Aragón, no tanto por el número de habitantes, como por su situación en las tierras prepirenaicas, lo que la hace la más norteña de todas, y por el papel de los moros en la producción, transporte y comercialización de la sal y de otros productos; pero a pesar de esa importancia, todavía está por hacer la historia completa de la misma. Todos los historiadores que se han referido a los moros de Naval lo han hecho someramente, tomando como base las noticias que proporcionan los documentos reales de los siglos XIII al XV sobre la villa de Naval, en los que los moros apenas son mencionados aunque todo cuanto se legisla les afecta como grupo mayoritario de población en un principio, si bien en el siglo XV nos vamos a encontrar ya una población mixta que apenas ha merecido la atención de los investigadores, limitándose las citas al posible número de habitantes, especialmente a partir del fogaje de 1495 o a su relación con el transporte, concretamente al de aceite ${ }^{20}$.

En este artículo se va a prescindir de los datos ya dados a conocer a partir de los fogajes y nos vamos a centrar exclusivamente en lo que la documentación nos da a conocer, que no es poco, especialmente aquellas reuniones que congregaban a un elevado número de vecinos, esos plenarios en los que la aljama sola o conjuntamente con cristianos y a veces con judíos, se reunía para tratar temas de interés colectivo, especialmente la venta de algún censal. Es evidente que la asistencia a esas asambleas no era obligatoria, y, aunque el tema a tratar fuera de suma importancia, los que en el momento estaban ausentes del lugar evidentemente no podían asistir, tampoco enfermos y muy ancianos, ni las viudas cabezas de familia, de manera que los datos que nos facilitan esos plenarios sólo pueden ser orientativos y habrá que complementarlos con las referencias a personas que por esas mismas fechas aparecen documentadas aunque no figuran en la relación de los asistentes.

Tenemos reuniones del plenario, bien como aljama o como miembros del concejo, de enero y febrero de 1476, marzo de 1478, marzo de 1483, mayo de 1484 , mayo de 1485 y octubre de 1511. En enero de 1476, los asistentes son catorce; en febrero, diecinueve; en 1478, veintidós; en 1483, quince; en 1484, dieciséis; en 1485, veinticinco, y en 1511, veintiocho. Como se ve, un número variable incluso en reuniones muy próximas en el tiempo, por lo que este elemento solo puede ser orientativo, si bien la cifra de asistentes en 1485

20.- M. Luisa Ledesma Rubio: Estudios sobre los mudéjares en Aragón, Teruel, Centro de Estudios Mudéjares, 1996, p. 84. 
y 1511 se acerca a los veintiséis fuegos que figuran en el censo de $1495^{21}$. Llama la atención la falta de interés por asistir a algunos plenarios, a pesar de que en ellos se abordan temas de gran importancia para la villa y la aljama.

El hecho de que se conserven las actas de dos reuniones en dos meses consecutivos de 1476 ha permitido conocer los nombres de los asistentes a ambas reuniones, y sumando los nombres y apellidos de todos ellos dan un total de veintiséis, el mismo número, prácticamente, que aparece en las reuniones de 1485 y 1511, de lo que podría deducirse que no hubo grandes cambios de población a lo largo de ese periodo. Pero, de todos modos, aún así hay que tomar con cuidado estos datos, porque si estudiamos todos los nombres de quienes aparecen mencionados en fechas próximas, nos encontramos con la sorpresa de que hay individuos que no figuran en la relación de los asistentes a las reuniones. Así, a los dieciséis presentes en la reunión de 1484 habría que añadir dieciocho personas más que aparecen en la documentación, a lo largo del año y en enero del año siguiente; todos ellos, por lo que parece, son cabezas de familia, incluida una mujer viuda, Zora Calvo, que actúa con sus hijos Jucé y Mahoma lo Burro de los que para distinguirlos de sus homónimos se hace constar la filiación, quizás también porque sean menores, razón por la cual no se han computado. Estamos, pues, ante una población que como mínimo contaba en ese momento con treinta y cuatro cabezas de familia, más de un $12 \%$ por encima de la cifra que dan las fuentes oficiales, y que legitima la teoría de algunos historiadores partidarios de poner en cuestión estos censos, al sospechar que hay ocultación de datos, algo que parece evidente. De hacer caso a $\mathrm{Madoz}^{22}$, que dice que las familias moriscas expulsadas de Naval fueron sesenta, parece confirmarse esa ocultación, aparte de un aumento demográfico que se nos antoja excesivo.

A partir de la documentación estudiada es imposible tener más información sobre la población, por ejemplo su dinámica demográfica. Como mucho, podemos intuir algún movimiento migratorio, como la noticia de Axa Franco, natural de Naval, casada en Barbastro con Mahoma Barrach y que al enviudar deja a sus hijos en su pueblo natal bajo la tutela de su hermano Brahim Franco $(1484,1485)$. Son cuatro los menores: Brahimico, Mahoma, Zora y Gaya, que muere antes del documento de 1485. En todo este proceso de tutoría y herencia, en el que se aplica la ley musulmana, interviene Mahoma de Mayo,

21.- M. Teresa Ferrer i Mallol: "Las comunidades mudéjares en la Corona de Aragón en el siglo XV: La población”, VIII Congreso Internacional sobre mudejarismo, Teruel 1999, pp. 27-153. Menciona la población de Naval en las pp. 46 y 63

22.- Referencia tomada de P. CAJAL: X siglos, p. 20. 
alfaquí de la aljama de Naval, como asesor jurídico ${ }^{23}$. Otro moro que por el apellido pudiera ser de Naval que encontramos en Barbastro es Brahim del Alamín, quien en 1426 pide a Juan Ximénez Cerdán, señor del castillo de Entenza y de la morería de Barbastro, que lo acoja como vasallo con todas las obligaciones inherentes, señal de que es un inmigrante nuevo en la ciudad $\mathrm{y}$, aunque no ponga la procedencia, el apellido nos lleva a Naval ${ }^{24}$; Brahim parece mantenerse en contacto con los moros de su pueblo y es testigo en un documento de 1434 de los navaleses Aça (Eyça) Navarro y Alí Navarro. Otros posibles emigrantes, estos a un lugar muy próximo, Salinas de Hoz, son Hazmet de Muça y Ovécar de Muça (1482 y 1515), cuyo apellido está documentado en Naval ya en 1412 .

También podemos saber de algún inmigrante gracias a los apellidos. Por ejemplo, Mahoma Maruán o Marguán, documentado en 1414, puede proceder de Huesca, donde el apellido es bastante común ${ }^{25}$ y, sin embargo, en Naval es el único que lo lleva. Otros apellidos oscenses y de Barbastro que en Naval sólo están documentados una vez son Ezcandar (1414) y Cernico (1468). Lo mismo ocurre con el apellido Alborayna (o Alboraybe), documentado en 1463 en la persona de Brahim y que es probable que proceda de Barbastro, y como los casos anteriores es un apellido que nunca más se repite; homónimos nos encontramos en Barbastro y emigrados a Huerto, alguno de ellos alfaquí . Dos hermanos, Eyça y Alí Navarro figuran en un documento de 1434 como Aça el Navarro y Alí el Navarro, y ese artículo "el" bien podría indicar su condición de navarros.

Al final del trabajo se incluye la relación nominal de todos los moros documentados en Naval y los años en los aparecen.

\section{LA ALJAMA}

Pocas referencias a la aljama tenemos fuera de los plenarios de los que algo ya hemos dicho y algo más se va a decir.

Es probable que en el pueblo hubiera un barrio de mayoría musulmana, porque en 1468 se habla de casas en la Morería de la villa, pero también veremos bienes inmuebles de judíos y moros contiguos y sitos en la plaza del

23.- Ánchel Conte Cazcarro: La aljama de moros de Barbastro, Barbastro, edición del autor, 2013, p. 94.

24.- Ibídem: p. 18.

25.- Ánchel Conte Cazcarro: La aljama de moros de Huesca, Huesca, Instituto de Estudios Altoaragoneses, 1996, pp. 59 y 242. 
lugar. El apellido Cotón está, sin duda, en relación con uno de los barrios de la villa, topónimo aún existente (figura 2); por la frecuencia con que aparecen moros así llamados podría pensarse que era uno de los lugares donde se concentraba la población mora.



Fig. 2. Barrio de Cotón, donde posiblemente habitaba la mayoría de población mora (Foto: Ánchel Conte) 
Este colectivo estaba perfectamente integrado en la vida de la villa, donde suponía casi la mitad de la población, como lo prueba, por ejemplo, el número de asistentes al plenario municipal de marzo de 1478, en el que hay veintidós cristianos, veintidós moros y siete judíos, recogido en un documento en latín, razón por la que se han respetado la grafía de los nombres de judíos, moros y cristianos tal como aparecen en la escritura:

ASISTENTES CRISTIANOS: Gaston de Moriello, justicia; Michael de Almaçorre, baile; Martinus de Linies, jurado; Johannes de Almalliello, jurado; Joannes Calvo, Raymundus de la Penyella, Ferdinandus de la Penyella, Benedictus de Esquerro, Franciscus de Panno, Jurdanus de Cosculluela, Johannes de Cenera, Bernardus Latrero, Sanctius Palacio, Petrus Moriello, Garcias Barbues, Petrus de Vitoria, Lupus de Moriello, Michael de Linies, Garcias Calvo, Garnavalla Berga, Johannes de Montornés y Albertus Costasoprani.

JUDÍOS: Jacob Anuçach, adelantado; Jucé Tello lo Cenich, adelantado; Yçach Abnaxeron, Barzella Trello, Yçach Ambron, Sensón Acaguel y Abraham Altexefi.

MOROS: Jahe de Fornos, alamín; Ali Galbán, adelantado; Mahoma Armeller, adelantado; Jucé de Barrio alias Romero, Abraym de Pueo, Abraym de Franco, Eyça de Burro, Muçot de Burro, administrador; Jucé lo Burro menor, Jucé de Calvo menor, Ceyt de lo Burro, Mahoma Dosmén, Mahoma Morellón, Abreaym lo Burro, Muça Jahe mayor, Mahoma de Franco, Osinen de Franco, Jucé lo Burro mayor, Jahe de Alfocén menor, Jucé de Ceyt, Jucé Jahe mayor y Mahoma de Mallos.

La ley por la que se regía su vida era la "sunna y xara", según se dice en 1485, y su fe queda manifestada en todos los casos en que juran, que lo hacen, según transcriben los escribanos cristianos, por bille ille illeua, bille ille e paraulas del Alcorán, bille ille e Ramadán, bille illeua e Alcorán,y fórmulas similares, simplificaciones del juramento de fe islámico: En el nombre de Dios el Clemente y el Misericordioso, o simplemente: doy fe (اشهـ). No hay duda de que en las relaciones entre ellos la ley imperante es la musulmana, pero en su relación con los cristianos, y especialmente en las acciones de carácter económico, los documentos insisten repetidamente en que se someten al Fuero de Aragón. No tenemos referencia alguna sobre su mezquita, aunque la hubo y así queda recogido en las capitulaciones, ya vistas, de Pedro I; tampoco hay noticia de una casa de juntas, si bien es dudoso que la hubiera, porque las reuniones del colectivo se celebran ante la puerta del castillo, igual que las reuniones del concejo, y a veces en una iglesia, tal como veremos más adelante. 
Sabemos que el responsable de gobierno era el alamín —en árabe, secretario-, y que había dos adelantados o jurados, un administrador, un conservador y un alfaquí, además, de un pagador y de un corredor o pregonero, cargo que recaía, a lo que parece, en cristianos, quizás porque fuera el vocero oficial de la villa; al menos el que conocemos no era musulmán, Peirot de Selgua (1483). La figura del alfaquí, especialista en la ley musulmana y con frecuencia notario ${ }^{26}$, tuvo que ser constante, pero sólo conocemos a Mahoma de Franco (1445) y a Mahoma de Mayo (1485), al que vemos intervenir en una cuestión de herencia y tutela que afecta a moros de Naval y Barbastro a la que me referiré más adelante; Mahoma es definido como alfaquí de la aljama, como si no hubiera más que uno. Casi todos los cargos de los que tenemos noticia son por un periodo de tiempo muy corto, y aunque sean pocos nos permiten comprobar que la vida política de la aljama no difería de las otras conocidas. No sabemos el sistema empleado para la elección de cargos, aunque no se puede descartar el de la insaculación, generalizado en el reino en el siglo XV. Es probable que los cargos, que por norma duraban un año, se eligieran a comienzos de año, porque en 1476 tenemos un alamín el 4 de enero, Jucé Barrio, y otro el 15 de febrero, Muçot lo Burro; y en 1485, el 6 de marzo lo era Brahim Franco y el 5 de mayo el cargo lo ostentaba de nuevo Muçot lo Burro. Lo mismo ocurre con los adelantados; por ejemplo, en marzo de 1484 son adelantados Eyça Calvo y Jucé de Ceyt y en mayo del mismo año lo es Jucé lo Burro, que repite el cargo que ya había tenido en 1483, lo que, como ocurría en $\mathrm{Huesca}^{27}$, prueba que no se podía ocupar el cargo dos años seguidos, pero sí debía aceptarse obligatoriamente si había transcurrido un año desde que había cesado el anterior mandato. Además de los mencionados, conocemos a los alamines Jahe Fornos (1478) y Brahim Franco (1483 y 1511) ${ }^{28}$, y a los adelantados Alí Galbán (1478), Mahoma Almeller (1478 y 1483), mientras que en 1485 Muçot lo Burro y Mahoma Almeller, aparecen como jurados. Las finanzas de la aljama debían de correr a cargo del administrador, cargo que podía estar duplicado, como ocurre en marzo de 1478, cuando son administradores Mahoma Morellón y Muçot lo Burro, que vuelve a repetir en 1485. El pagador que conocemos es Jucé Franco (1486), y el conservador, cuya función es imposible conocer

26.- Asunción Blasco Martínez: "Notarios Mudéjares de Aragón (siglos XIV y XV), Aragón en la Edad Media, X-XI (1993), pp. 109-134.

Á. ConTE: la aljama de Barbastro, p. 85.

27.- Idem: La aljama de Huesca, pp. 41-42.

28.- En la relación aparecen también Çalema el Alamín y Amet el Alamín, pero no se trata de su cargo, sino de su filiación; en la aljama sólo podía haber un alamín, algo que parece ignorar Cajal (P. CAJAL: $X$ siglos, p. 17) cuando dice que había tres alamines. 
a partir del documento, es mencionado, sin nombre, en $1486^{29}$. En un documento de marzo de 1483 se hace constar que hay tres adelantados: Mahoma Almeller, Jucé Burro y Jucé Ceyt, y, aunque por la documentación todo apunta a que habitualmente sólo eran dos, no se puede descartar que en momentos concretos, como este, fueran tres.

Como en el resto de la aljamas, los responsables de su gobierno eran los encargados de convocar mediante pregón, o avisando de casa en casa, para los plenarios, que regularmente se tenían que celebrar para tratar todos los asuntos que afectaban al colectivo; pero, lamentablemente, sólo nos ha llegado conocimiento de los referentes a la venta de censales o a la reunión del concejo para elegir un administrador, como se verá, de modo que aspectos como la regulación de la vida del colectivo, la administración de la aljama, su economía, su relación con el culto y la asistencia social, por ejemplo, quedan en la oscuridad.

\subsection{Participación de la aljama en la vida de la villa}

Es de suponer que desde los primeros momentos tras la reconquista, moros judíos y cristianos, en proporción que no sabemos, formaran el concejo general del pueblo, tal como nos ha llegado hasta el momento que estudiamos, aunque numéricamente es probable algún cambio sustancial tras la invasión en 1320 de los pastorells, que se encarnizaron en su afán devastador en las aljamas de judíos y moros y asesinaron a los judíos del vecino pueblo de Monclús, y, con la colaboración de gentes del lugar, atacaron la morería de $\mathrm{Naval}^{30}$. En el siglo XV vemos a judíos y sarracenos formando parte de pleno derecho del concello de la villa y están presentes en los actos de interés general; eso debía de ser así en todos los campos, aunque sólo tengamos constancia de la corresponsabilidad en los censales que vende la villa para salvar momentos de apuros económicos y en una ocasión (octubre de 1511) ${ }^{31}$, para nombrar procuradores de la administración de la villa, del castillo y especialmente de las rentas de la sal, tema que debió de interesar especialmente al colectivo moro, ya que el número de asistentes al acto (28) es el más alto de los regis-

29.- No hay noticia de otros conservadores en las aljamas estudiadas, y tal vez estemos ante el caso de un "tesorero", porque en el documento en que aparece figura como pagador de la pensión de un censo.

30.- Jaume RiERA I SANS: "Los pastorells en Barbastro (julio 1320)", Aragón en la Edad Media, XVIII, (2004), pp. 299-336.

31.- P. Cajal: $X$ siglos, pp 16-17, data el documento en 1512, error debido a que este protocolo corresponde a los años 1511-1512. Tampoco hay coincidencia plena en la transcripción de los nombres. Fecha y nombres los toma de José Cabezudo Astrain: "Los moros de Barbastro y la cuestión de la mezquita”, Miscelánea de Estudios Árabes y Hebraicos, XI, (1962), pp. 115-120. 
trados a lo largo de su historia, cosa normal si tenemos en cuenta que la base económica de la villa es la producción y el comercio de la sal. La relación de moros asistentes es la que sigue: Brahim de Franquo, alamín; Çalema el Alamín, Mahoma de Ceyt, Mahoma Galter, Mahoma de Obéquar, Brahim de Barrio alias Cabero, Eyça Nabarro, Jahel Cotón, Alí de Barrio, Mahoma Ferrero, Çalema de Franquí, Mahoma Galbán, Mahoma Jahel, Jahel Galbán, Jucé de Calvo, Mahoma de Franquo menor, Eyça Çanson, Brahim de Franco, Amet el Alamín, Moferriz Cotón, Mahoma Pasavallas, Mahoma Çalema, Jucé de Barrio, Mahoma de Franquo, Brahem lo Burro menor, Brahem lo Burro mayor y los testigos Jucé de Pueyo y Moferiz Alfocén.

Vale la pena insistir en que, aparte de participar de pleno derecho en la vida del concejo, la aljama como tal tenía autonomía plena para tratar los asuntos que le concernían y, como ya se ha dicho, regulaba su funcionamiento de acuerdo con la legislación musulmana y el pacto dado en el momento de la reconquista (1099), en el que se recogían una serie de derechos y obligaciones dadas por Pedro I, consistentes en ingenuidad y franqueza de parias y azofras, por ejemplo, y también, como colectivo, tenía obligaciones que arrancaban de antiguo y que con toda probabilidad se mantuvieron a lo largo de los tiempos, como el pago de 300 sueldos anuales por las eras salineras que explotaban, como se ha visto en la introducción histórica.

La reunión de concello y aljama de 1511, citada anteriormente, convocada de casa en casa por los jurados cristianos y el alamín, nos descubre que a veces el plenario de moros y cristianos, concello y aljama, se reúne en la iglesia de San Miguel (figura 3), tal como dice la escritura, "do segunt que otras vegadas el dicho concello e aljama es costumbrado plegar, congregar e ajustarse", lo que viene a confirmar, no sólo una convivencia total entre una comunidad y la otra, sino la ausencia de cualquier prejuicio de tipo religioso.

Es posible que la reunión no se celebrase en el interior del templo debido a la presencia de musulmanes, pero el documento no especifica tampoco que la reunión tuviera lugar fuera del mismo, cosa que sí ocurre cuando se celebra en el castillo, que se indica que se hace a las puertas del mismo. El templo ha desaparecido, pero por una escritura de 1627 sabemos que estaba en las inmediaciones del cementerio de los cristianos nuevos, que es vendido en parte en ese documento, según el bastardelo de visitas episcopales ${ }^{32}$, y que posiblemente fuera la vieja almecora musulmana.

32.- ADB. Bastardelo de Visitas iniciado en 1624. Legajo 577. Accesible en: http://servicios.aragon. es.etno/gestion? 


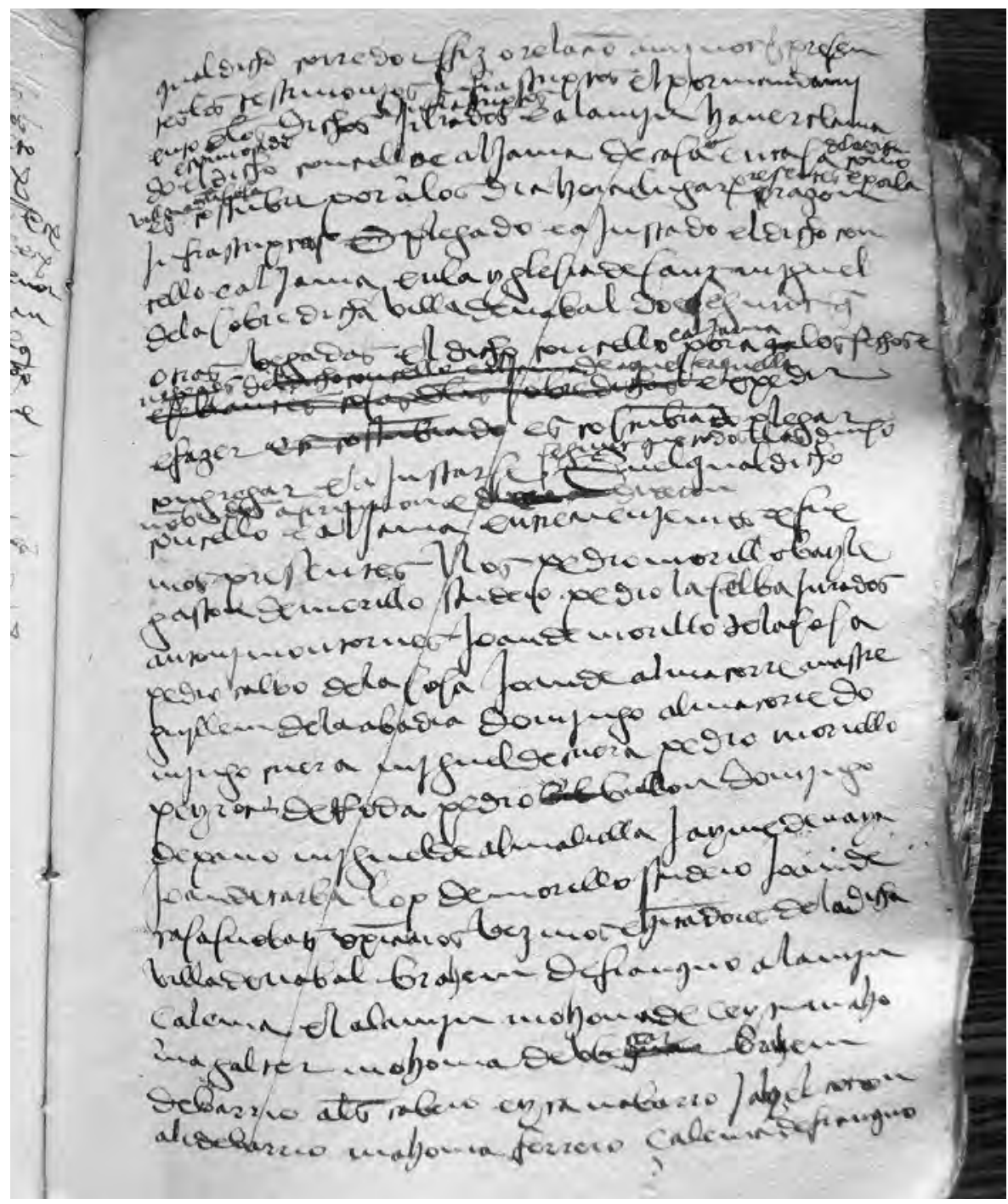

Fig. 3. AMB, Protocolo de Bernado de Toledo,1511-1512,f. 62 r, en el que se recoge la reunión el 3 de octubre de 1511 del concello y la aljama en la iglesia de San Miguel (Foto: Jesús Paraíso).

(...) asimismo dio licencia, permiso y facultad su Señoría (el obispo fray Alonso de Requesens y Fenollet) para que puedan vender al dicho Jerónimo Sanz de Broto un pedazo de cementerio que era de cristianos nuevos junto a la ermita de San Miguel (...) 


\subsection{Endeudamiento: los censales}

A pesar de ser un pueblo rico, especialmente por la producción de sal y el monopolio de su comercialización en un vasto territorio, el concejo se endeuda repetidamente a lo largo del siglo $\mathrm{XV}$, como vamos a ir viendo detenidamente. Este endeudamiento, registrado en algunos documentos notariales, obliga a las tres comunidades, aunque excepcionalmente veremos que los moros, haciendo uso de su autonomía, venden censales como aljama y no participan en ventas hechas por la villa. En todos los casos, los prestamistas son miembros de la burguesía y pequeña nobleza de la ciudad de Barbastro, capital natural de la comarca.

A comienzos de 1476 se reúne el concejo de cristianos, judíos y moros de Naval a las puertas del castillo, según costumbre, para vender a Andreu Verdeguer un censal de 115 sueldos y 8 dineros por precio de 1400 sueldos. Los moros citados — se recogen los nombres literalmente- son: Jucé del Barrio, alamín; Mahoma de Franco, Mahoma de Mayo, Abraym Escudero, Moferig del Fozen, Juzé lo Burro, Mozot del Burro, Ovequa de Gaycho, Ovequa Almeler, Jucé lo Burro menor, Gahen (Jahe) de Alfozén, Gahe de Fornos, Azmet de Franco y Muza Jahe menor. Juran los cristianos por los evangelios, los judíos por los diez mandamientos y los moros por bille ille. Está claro que el endeudamiento afecta a la totalidad de la población, por eso resulta extraño que un mes después el alamín Moçot (o Muçot) lo Burro se comprometa con Verdeguer mediante una comanda por el importe de lo recibido por la villa con la venta del censal, como si sólo el colectivo de moros pudiera hacer frente a la deuda; de ser así nos mostraría su mejor posición económica que la de cristianos y moros. El censal pasa por venta a manos de Antonio Verdeguer en marzo de 1476, si bien en este documento aparece que tiene una renta de 116 sueldos, en lugar de los 115 sueldos y 9 dineros que daba en el momento en que se vendió a Andreu Verdeguer.

La autonomía de la aljama en el campo económico queda reflejada en la venta que hace de un censal de 400 sueldos de propiedad y 28 sueldos de pensión. La operación tiene lugar en 1471 y se hace a Juan Díez, pero no tenemos información de la misma hasta julio de 1478, cuando vemos que, en nombre del colectivo, Mahoma Almalech (acaso sea realmente Almeller) puede luir la mitad de la deuda, entregando 200 sueldos al judeoconverso Antón de Santángel ${ }^{33}$, que había comprado el censo en fecha indeterminada a un segundo propietario, Salvador Verdeguer, lo que manifiesta la movilidad del dinero entre la aristocracia urbana. Este endeudamiento particular de la 
aljama es quizás la razón por la que en la venta de un censal que hace la villa en marzo de 1478 se desmarcara parcialmente. El largo documento en latín recoge todos los nombres de los asistentes de las tres religiones (visto en el apartado dedicado a la aljama). Parece que el documento compromete a todos, pero realmente se da la nota curiosa de que judíos, moros y cristianos reconocen tener una comanda del comprador del censo, el mercader Juan Díez; y los judíos, por su parte, aceptan una de 850 sueldos, aunque se reconoce que como esos 850 sueldos son en "beneficio" de los cristianos, son estos quienes se responsabilizan de pagar la comanda, de modo que del total de 1200 sueldos, que rentan 100 suelos anuales, realmente sólo 350 (en el documento por error pone 300) obligan a las tres comunidades, y los 850 restantes a los cristianos, o al menos así se da a entender al aceptar las comandas que obligaban al receptor y por la que ponen como garantía numerosos bienes en la villa, especialmente casas y eras salineras pertenecientes a las tres comunidades. El censal se cancela en 1493, expulsados ya los judíos. En una serie de anotaciones casi taquigráficas en el documento realizadas posteriormente a la cancelación, parece que se plantean problemas muy serios con este censal, acaso porque quedó sin pagar la parte correspondiente a los judíos, aunque eso no pase de ser una suposición. Lo que sí queda claro es que el litigio se da entre la villa y el rey cuando la villa ya no era de realengo. La dimensión del problema se nos escapa, pero llega a intervenir la Inquisición. En notas marginales inconexas y de difícil interpretación, fechadas en 1517, aparecen mencionados Lanuza y Díez, señores del castillo de Entenza y de la aljama de Barbastro, sin que lleguemos a saber qué relación podían tener con este viejo censal que oficialmente se había cancelado veinticuatro años antes, y quizás no sea más que un error del escribano, a no ser que el heredero de Juan Díez, comprador de este censal, sea Pedro Díez, justicia de Barbastro y casado con Isabel de Rebolledo, señora del castillo de Entenza y de la morería de Barbastro, que se había enfrentado a Juan Miguel Lanuza y Entenza, arrebatándole por vía legal castillo y aljama (1517) ${ }^{34}$.

De nuevo en marzo de 1483 vemos a la aljama en solitario vender a Leonor de Santángel, viuda de Luis de Santángel, un censal de 400 sueldos de propiedad y 33 sueldos y 4 dineros censales de pensión perpetua. El acuerdo se toma reunida la aljama a las puertas del castillo, convocada por el corredor de la misma, Peirot de Selgua, por mandamiento del alamín y adelantados. Asisten - conservamos la forma en que aparecen escritos los nombres en el documento-: Braym de Franquo, alamín; Mahoma Almeler, Juzé lo Burro y Juzé de Ceyt adelantados; Jafe de Alfozén, Juzé de Calbo, Hazmet Franquo, 
Mahoma Franquo, Mahoma Navarro, Juzé de Barrio, Jahe de Alfozén mayor, Mozot de lo Burro, Jahe de Fornos y Mahoma Morellón. Juran los moros por bille ille alladí y paraulas del Alcorán. Parece normal que, cuando cuatro días después la villa vende a Francés de Espluga un censo de 1300 sueldos de propiedad, la aljama no participara, teniendo en cuenta el endeudamiento previo. No ocurre lo mismo en mayo de 1484, cuando la villa vende un censal a Pedro de Santángel de 40 sueldos censales y 500 sueldos de valor de propiedad. Cristianos, judíos y moros participan en el acto. Por la aljama de moros asisten: el alamín Muçot lo Burro; los adelantados Jucé lo Burro e Yça de Calbo; Jucé lo Burro menor, Jucé lo Burro mayor, Mahoma de Franquo, Muçot de Jahe, Mahoma de Pueyo, Jahe de Alfozén, Jahe de Muça, Braym de Calbo, Amet de Franquo, Jucé de Zeyt, Mahoma lo Burro y Jahe de Alfozén, y como testigo firma Mahoma Verdugo.

Algo más costoso es el censo vendido en 1485 a Pedro Díez; son 101 sueldos censales por valor de 1350 sueldos; el censal se pagará cada año el 8 de marzo. En marzo de 1496 se cancela y se libera la villa del pago. Para la venta del censal, se reúne el concello de Naval, integrado por cristianos, judíos y moros, como es habitual a la puerta del castillo, presididos por las autoridades de las tres comunidades en un acto que parece especial y que, algo poco usual en las ventas de censales que estamos viendo, se escribe en latín, lo que en el marco en que nos estamos moviendo puede tomarse como una forma de marcar la solemnidad que se le da. Todos los asistentes han quedado recogidos en el estudio del apartado dedicado a la aljama, son veintidós moros, otros tantos cristianos y siete judíos, presididos por las autoridades de cada comunidad: justicia y baile cristianos, adelantados judíos y alamín y adelantados moros.

No hay más datos sobre este campo, salvo la certificación de un pago de 100 sueldos de pensión anual en agosto de 1486 a Juan Verdeguer, como procurador de su hermano Andreu, que hace en nombre de toda la aljama Jucé Franco y el conservador de la misma, sin que se especifique a qué censal corresponde.

Aparte de las operaciones dinerarias anteriores, la documentación nos permite adivinar alguna actividad económica por parte de la aljama como colectivo, y aunque sólo nos haya llegado un dato es bastante significativo, ya que se trata de la posesión de eras salineras (1479), lo que le permitiría comercializar el producto de esas salinas y obtener unos ingresos que ayudarían al sostén de una serie de servicios, como el mantenimiento de la mezquita y obras de asistencia, que por ley vienen obligadas. 


\section{Aspectos SOCiOECONÓMicos}

\subsection{Los oficios}

La documentación es bastante pobre a la hora de informarnos sobre los oficios de los moros de Naval, pero no de sus posibles actividades económicas. Por ejemplo, tenemos una relación numerosa de moros que poseían tierras de cultivo y sin embargo apenas aparecen gentes que desempeñen el oficio de labrador. Lo mismo hay que decir de las "eras salineras", que muchos moros, e incluso la aljama, poseían, y sin embargo ninguno es mencionado como "salinero". Y qué decir de las pruebas irrefutables de la relación de los moros con el comercio - bien como trajineros o como mercaderes-, que contrastan con las pocas referencias sobre ambas profesiones. Atendiendo exclusivamente a lo que las escrituras definen con claridad, disponemos de unos pocos datos que pasamos a recoger.

Es impensable un colectivo musulmán sin la presencia de alfaquíes, que, recordamos, no sólo eran asesores jurídicos por su condición de especialistas en la ley islámica, sino que además, en una sociedad mayoritariamente iletrada, ejercían la función de escribanos e incluso notarios, tanto para los documentos privados como para los públicos ${ }^{35}$, y así, se define como alfaquí de la aljama a Mahoma de Mayo (1485). Anteriormente, se tiene noticia de otro alfaquí: Mahoma Franco (1445), que, aunque no se haga constar, quizás también lo fuera de la aljama; no parece que en la pequeña comunidad pudiera haber simultáneamente varios alfaquíes.

Oficios que por ley debe haber en todos los colectivos musulmanes son un carnicero y un matarife; aunque no siempre, ambos oficios pueden coincidir en ocasiones en la misma persona. A pesar de que necesariamente tuvo que haberlos durante toda la historia de la comunidad, sólo tenemos el nombre de uno: Azmet lo Burro, mencionado entre 1485 y 1522 como "el carnicero de Naval", que, teniendo en cuenta el número de habitantes, es muy probable que también fuera el matarife. Treinta y siete años de actividad continuada parecen indicar que el oficio se ejercía de por vida, y el hecho de que se le defina como el "el carnicero de Naval" nos invita a pensar que era el único.

Una de las actividades económicas que ha marcado la vida de Naval, aparte de las salinas, es la ollería, y sin embargo no hay ni una sola mención concreta a un ollero ni tejero, sólo hay referencias a sendos individuos que con toda probabilidad trabajaron en el sector, aunque separados por más de un siglo. A comienzos del siglo XVI sabemos de la compra de un horno que hace Eyça del 
Royo a Brahim Jahel (1516); el horno está situado en la partida de Valfarta, lejos del recinto urbano, lo que parece indicar que no es un horno destinado a la cocción de pan, y todo apunta a que fuera el de un alfar, de modo que tendríamos a Eyça y Brahim como posibles alfareros. Un siglo antes (1403), en el documento más antiguo de los estudiados, encontramos a Ramón de Pisa, señor de este pequeño pueblo, que encarga 60 cahíces de calcina al moro Muça Minyana. Si el señor de este lugar, situado dentro del actual término de Naval, encarga la calcina a un navalés será porque allí estarían los hornos más cercanos, y para el trasporte de ese material se podía recurrir, sin duda, a los numerosos trajineros/arrieros de Naval. No debe extrañar que en los hornos de los alfareros se fabricara calcina, ya que era habitual, y el ejemplo más próximo en el espacio y el tiempo lo tenemos en Barbastro en 1445, con los tejeros Farax del Alguacil y Mahoma de Sasa ${ }^{36}$. Según $\mathrm{M}^{\mathrm{a}}$ Isabel Álvaro no hay documentos que prueben la existencia de alfares en Naval durante la Edad Media ${ }^{37}$. No obstante, las referencias que hemos encontrado, si bien sean indirectas, parecen probar que en el siglo XV había gente relacionada con el oficio y, además, que la idea de que es un trabajo vinculado a los moros no está fuera de lugar.

Oficios frecuentes entre los moros de las aljamas estudiadas en la zona es el de herreros y caldereros, al menos en Huesca y Barbastro la actividad metalúrgica es la más importante, cosa que no parece que ocurriera en Naval. Conocemos al calderero Mahoma Menescal (1524) y al herrero Jucé Cabero, quien establece en 1483 una compañía con el ainsetano Juan Senz y los barbastrenses Jaime Senz y Miguel Lasierra para explotar una farga (fragua) y vender la producción. El caso es muy interesante tanto desde el punto de vista económico (creación de una compañía y comercialización del producto) como social (moros y cristianos unidos en una misma empresa). El hecho de que la compañía esté formada por gentes de Aínsa, Naval y Huesca nos da pistas sobre la zona en la que se comercializaba el producto de esta herrería. Algunos herreros, generalmente los de más categoría, estaban especializados en la sanación de animales de labor (menescales), y al que conocemos, Mahoma Burro, se le identifica como "el menescal de Naval" (1485), de lo que podríamos deducir que sólo había uno, al menos en aquel momento. Finalmente, en 1484, está documentada la compra que Jahe de Fornos alias Moreno hace a Cristóbal Capiella y Martina Santacoloma, emigrados a Barbastro, por 600 sueldos, de un obrador, sin que se sepa qué se producía

36.- Á. Conte: La aljama de Barbastro, p. 45.

37.- María Isabel Álvaro Zamora: "La ollería de Naval (Huesca)", Argensola, no 71-72, (1977), pp. 71-94. 
en él; se compra junto con una casa y un campo; casa y obrador están en la plaza del pueblo y limitan con propiedades de los judíos Abraham Acaguel y Faym Almaxegon, lo que, como se apuntaba, parece indicar que no existía separación física entre la habitación y negocios de las diferentes comunidades.

Más adelante se dará cumplida cuenta de las explotaciones agrarias en manos de los musulmanes. Pero como labrador sólo aparece mencionado Brahim Franco (1500), que era lo suficientemente rico como para comprar unas casas en Barbastro por la elevada cantidad de 1700 sueldos. Quizás, aunque aparezca como labrador, tendría alguna otra actividad que le permitiría disponer de liquidez para llevar a cabo una inversión de ese calibre.

Del comercio se hablará ampliamente más adelante al estudiar las comandas, pero como mercaderes y trajineros aparecen mencionados poquísimos, aunque todo apunta a que eran oficios muy frecuentes, o al menos han dejado mucha huella documental en las numerosas comandas que toman o dan muchos moros de la villa. Tal vez el caso más evidente sea el de Mahoma Franco, mercader que actúa en más de una ocasión con Jucé lo Burro, y que en 1467 llevaron a cabo una acción comercial en Barbastro, donde los jurados de la ciudad les aprehendieron catorce quintales de aceite y cuatro mulos; se comprometen a dar a caplienta ${ }^{38}$ la ejecución y a depositar 1000 sueldos que se obligan a restituir. El resultado final del conflicto nos es desconocido, pero lo que nos queda claro es que estamos ante dos mercaderes cuyo movimiento de capital, a tenor de los 1000 sueldos dejados en depósito, no es poco. Antes, en 1459, sabemos que Jucé había comprado ovejas en Bestué a Juan Puértolas y que seguía pendiente el pago de 300 sueldos. De Mahoma Franco sabemos que en 1485 comercia con aceite en Colungo, donde da una comanda de 10 quintales de olio bueno, limpio y mercadero a Domingo Laspuertas. Otro mercader mencionado como tal es Brahim lo Burro, que nombra numerosos procuradores (1519) para cobrar y hacer albaranes, tal como más adelante se verá. Como trajinero es definido Brahim Jahel en 1516, pero como luego veremos al hablar del comercio debieron ser muchos los moros dedicados a este oficio, bien como mercaderes o como simples arrieros, y de hecho la villa de Naval, a lo largo de su historia, ha sido un lugar que ha dado muchos trajineros.

Por fin, nos encontramos con una serie de personas a las que se les pone como apellido un oficio y que en todos los casos no vuelven a repetirse, de modo que se crea la duda de si realmente es un apellido o estamos ante unos

38.- Francisco Javier García Marco en "Tipología documental e investigación histórica: las actas notariales como reflejo de la evolución de la sociedad aragonesa en la Edad Media”, Aragón en la Edad Media, IX, (1991), pp. 31-54, en la p. 49 habla de la «caplieuta» o «capción». 
artesanos a los que se les identifica por el oficio. Así, Mahoma Ferrero (1511), Jucé Çapatero (1501), Jucé Cubero (1485) y Jahe Forner, (1488), acaso un hornero que también era imprescindible en la comunidad, como imprescindible era un zapatero, oficio frecuente entre los moros del Altoaragón ${ }^{39}$. No menos necesarias eran las cubas para el almacenaje de vino y aceite, producto éste con el que comerciaban, como se ha visto, los navaleses.

\subsection{Actividad salinera}

La sal va unida a la historia de la villa y llega hasta nuestros días. Fue Jaime I, como ya se vio, quien favoreció especialmente las salinas concediendo el monopolio de la venta de la sal (1274) en una amplia región y mandando construir el alfolí, que aún hoy sobrevive, para el almacenaje y control de la producción. Del edificio original queda poco o nada, y el que hoy vemos tiene todo el aspecto de ser una obra renacentista (figura 4).

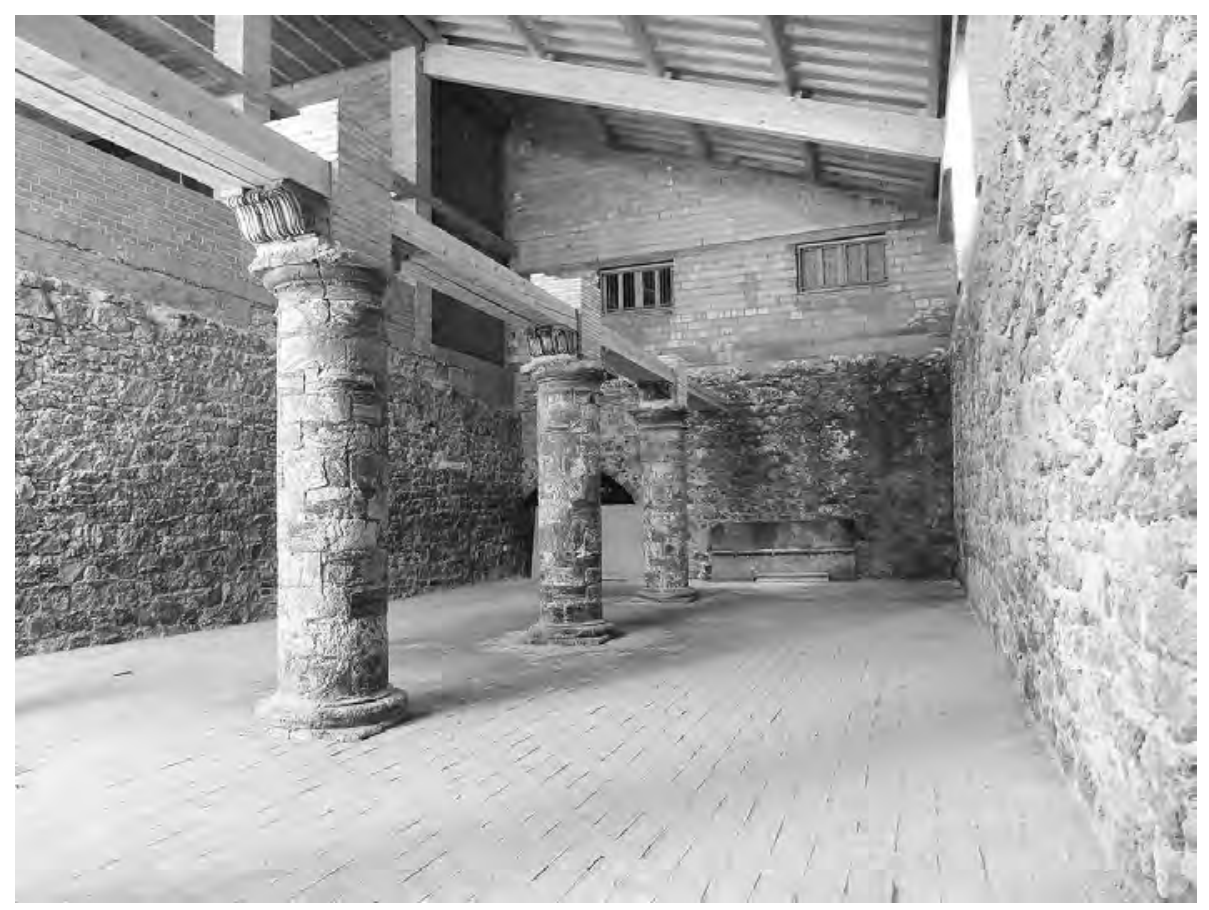

Fig. 4. Estado actual del alfolí (Foto: Ánchel Conte)

39.- Á. Conte: La aljama de Huesca, p. 212; La aljama de Barbastro, p. 141. 
En 1280, la villa se compromete a vender a Pedro III toda su producción de $\mathrm{sal}^{40}$ y no es de extrañar que los reyes siguieran manteniendo su interés por las salinas y por la defensa de la villa ya que era uno de los productos de mercado más apreciados.

Cristianos, judíos y moros explotaron las salinas a lo largo de la Edad Media, si bien no tenemos datos concretos de en qué proporción las "eras salineras", como se las define en la documentación, se repartían entre los tres grupos, aunque ya hemos dicho que tras el pacto entre Naval y Pedro I (1099) las salinas quedaron en manos de los propietarios moros, mas los reyes muchas veces pagaron los favores recibidos con la concesión de salinas a la aristocracia del reino. Pero no vamos a entrar en ello por no ser objeto de esta trabajo, sino que nos referiremos exclusivamente a cuantos datos nos da la documentación sobre la propiedad de salinas por los moros en el siglo $\mathrm{XV}$, faltando cualquier referencia a su comercialización, aunque es innegable que los trajineros y mercaderes navaleses la distribuyeron por su vasta red comercial desde el alfolí de la villa. Parece que estas salinas se poseían francas, y sólo tenemos referencia de unas eras de sal no francas por la compra de tres que en 1515 hace Brahim lo Burro hijo de Muçot a Mahoma Benganzin por 900 sueldos, cantidad elevada y que nos da idea del valor de este tipo de explotación; estaban localizadas en uno de lo salinares que se han explotado hasta época reciente, Barranco Ranero, y pagaban treudo de 6 dineros al monasterio de Sijena. Estas eras están dotadas de cabanyas, adulas, mascadineras y maneficios. Se nos escapa el sentido de mascadineras, pero la breve descripción demuestra que a lo largo de siglos se ha mantenido el método de explotación. El agua, como aún es hoy visible, se trasportaba desde una poza general a las eras a través de canales de madera por turno (adúla en árabe dialectal andalusí, según la RAE, significa campo que recibe riego por turno). Una vez obtenida la sal, con rastrillos y palas (los maneficios o herramientas de que habla el documento) se amontonaba hasta el secado total, posteriormente se almacenaba en las cabañas hasta que era transportada al alfolí.

Salvo el caso visto de las eras treuderas a Sijena, da la impresión de que el resto de eras salineras están en propiedad plena. Siguiendo un orden cronológico, la documentación nos informa de los siguientes moros que tienen salinas. Mahoma Morellón y Alí lo Manco (1465), sin especificar localización ni número, pero se habla de ellas en plural; Jucé Jahe en El Ranero, Brahim Franco mayor y Muça lo Burro en La Rolda (1478). En 1479, Mahoma Franco compra dos eras a Mahoma Dormen por 90 sueldos, lo que nos indica

40.- P. Cajal: $X$ siglos, p. 8. 
posiblemente la necesidad del vendedor por lo bajo del precio; se ubican en el Camino de Ranero, y limitan con las de Jucé Franco y con unas de la aljama, la única referencia que tenemos a un medio de producción propiedad del colectivo. En La Rolda tiene dos eras Jucé Reycon alias Royo que limitan con las dos de Jucé Alfocén; Jucé Burro y Jucé Barrio, una era cada uno (1481), y una cada uno poseen Ovécar Cotón, Brahim Burro, Eyça Burro y Jucé Burro menor (1484). En La Rolda, Brahim Burro tiene dos eras y otras Brahim Burro(1484), y eras sin especificar número y lugar tienen en 1485 Muça Jahe, Ovécar Alfocén, Jahe Alfocén, Muçot lo Burro, Mahoma Franco y Jucé Jahe. El mismo año, en La Rolda, sabemos de las eras de Jahe Alfocén alias Ferrachico y Ovécar Cotón, que por los límites no coincide con la indicada antes. Algunos tienen un buen número de eras, como es el caso del ya mencionado Jahe Muça, que en una comanda que toma de Salvador Santángel de Barbastro obliga como garantía cinco (1485); tres eras tiene Brahim Gael (Jahel) (1500), y el mismo número posee en El Ranero Brahim Burro, hijo de Muçot (1515), de las que ya antes hemos hablado. En otro salinar, El Pallero, tiene eras Jahe Alfocén, junto a las de Mahoma Franco y Ovécar de Alfocén (1485), todas ellas junto al barranco, y dos eras poseen en 1487 Jahe Afocén (tal vez las ya vistas) y Moçot lo Burro. La última referencia que tenemos data de 1515 y por ella sabemos que en El Ranero tiene unas eras Brahim Calvo.

Como se ve, un buen número de moros tenían en la producción de sal una fuente de ingresos digna de consideración, y en algún caso, excepcional, porque tres o cinco eras suponían una riqueza notable, a tenor de lo que se pagaba por ellas y del precio de la sal, cuya venta estaba asegurada por el monopolio que tenía Naval por los privilegios reales citados. Con toda seguridad, aunque no se haga mención concreta, la sal sería uno de los productos con los que comerciaban trajineros y mercaderes moros, de lo que luego se habla.

\subsection{Actividad agrícola}

Pese a la falta de noticias concretas, la totalidad de moros debieron de tener algún tipo de explotación agraria y en algunos casos debía de ser la actividad principal, quizás por eso apenas aparecen referencias a las tierras y se dan pocos casos de compraventa. La mayor parte de las citas documentales son casos en los que se ponen las tierras como garantía en acciones dinerarias de distinta índole. Tierras cerealistas y cultivos como la vid, el almendro y el olivo, además de pequeños huertos, conforman el paisaje agrario tradicional de la zona, y salvo el caso de los almendros, de una u otra manera se va a ver reflejado, directa o indirectamente en las escrituras. Sobre la extensión de las 
explotaciones y otras características no hay dato alguno, aunque sabemos que el uso del buey está bastante extendido en el campo; no obstante, todos los animales de labor que aparecen en poder de los moros navaleses son mulos, excepto dos casos: un asno en manos de Jahe Alfocén alias Ferrachico(1488), y un rocín que tiene Brahim lo Burro (1484). Nunca se habla de bueyes, que sin duda también emplearían.

Cuando el documento habla de "campo" hay que entender que se trata de tierra cerealista, porque si hay algún tipo de cultivo especial se especifica, como es el caso de un campo con vides (1468) y algunas referencias a campos con olivar $(1464,1469)$. Los cultivos de huerta no son mencionados, pero tenemos referencia de una acequia vecinal, concretamente la del barranco de El Ranero, si bien es probable que estemos ante una acequia, no para el riego, sino para alimentar los pozos de las salinas, y hay una partida, llamada O Güerto, en la que posee tierra Eyça Calvo (1478). Aparte de la mención al aceite como producto de mercado, no cabe duda de que el cultivo del olivo es de los más preciados, y prueba de ello son las inversiones que algún moro de Naval lleva a cabo fuera de su villa para comprar olivares; concretamente, en 1484, Jucé de Canero hace en el mes de abril dos compras: una en Coscojuela (Cosculluela) de Fantova, donde se hace con un olivar de Antoni de Benedets, en la partida de Lo Ferron, por 201 sueldos, a la vez que le compra un campo en término de Lo Puyal y otro en La Valle; al tiempo, alquila estas tierras al vendedor a cambio de que pague la peyta y la quiesta (sic) a las que el comprador estaba obligado y, además, le entregue un quintal de aceite del año y una parte de la cosecha, posiblemente cereal. En la otra operación, efectuada el mismo día, compra a Esteban Fierro un olivar en Hoz, en la partida de Lo Arnal, también por 201 sueldos. No puede descartarse que Canero se moviera por toda la comarca como trajinero o como vendedor, así parecen demostrarlo sus adquisiciones y el hecho de que fuera procurador del ainsetano Juan de Sanvicente (1471). Sendos olivares tienen Jucé lo Burro (1464) y Mahoma Franco (1485). Campo con vides posee Alí Galbán (1468), y una viña, además de un campo y tiras, compra el honorable Mahoma de Franco a García Calvo por 330 sueldos (1481).

El resto de las referencias hablan simplemente de campos o tierras. Son bastante numerosas, por lo que no es aventurado pensar que la mayoría de los moros de la villa tenían algún campo, y de ahí también la importancia de los animales de labor, que podrían servir también para el transporte de mercancías; es el caso de Jucé lo Burro, al que hemos visto comerciar con aceite y mulas y que en 1464 deja como garantía un mulo. Todas las referencias sobre caballerías se deben a que se ponen como garantía en acciones de compraventa o de comanda. Cuando la misma persona tiene más de un animal 
podríamos estar ante trajineros, aunque nada se diga al respecto, salvo en el caso del trajinero Brahim Jahel, que pone tres mulos como garantía; pero son varios los que tienen más de un animal sin que conste su oficio: Brahim lo Burro y Brahim Calvo (1483), y Jahe Alfocén alias Ferrachico y Brahim Calvo (1485). De unos cuantos más sabemos que tienen mulas: Eyça Navarro (1458), Mahoma Galbán (1464), Alí Galbán(1471) y Azmet lo Burro (1506). Muy pocos ejemplos para lo que tuvo que ser la realidad.

Salvo excepciones, los campos mencionados se ofrecen como garantía en operaciones dinerarias, y al relacionar los campos limítrofes nos ha permitido saber que muchas familias tuvieron tierras de cultivo, transmitidas desde la reconquista del lugar, que no supuso la pérdida de patrimonio para los moros que decidieron continuar viviendo en él. Muchos campos, que luego veremos, no sabemos en qué partida se encontraban, pero de otros tenemos la localización, y se está en condiciones de decir que la partida en la que mayor número de fincas tenían los moros era Renaldo (hoy Reinaldo) ${ }^{41}$, donde en 1481 se encuentran campos de Mahoma de Mallos, Eyça de Calvo, Jucé Burro, Jucé Barrio y Brahim Calvo. En la partida de Los Corrales, hay campos de Mahoma Burro, Mahoma Manco y Mahoma Calvo (1465). En Fontellas, está documentado uno de Brahim Calvo (1503), quien en 1485 aparece como propietario de un campo en Fuentes Calientes. En la partida de La Lacuna tienen sendos campos Eyça Navarro (1463) y Mahoma Cotón, que tiene otro en La Rolda(1458). En Las Francas en 1481 tenemos documentados los campos de Jahe Alfocén; el mismo año, en Serrullye, hay uno de Brahim lo Burro.

Es probable que algunas de las tierras y bienes de la villa estuvieran sin explotar o subexplotadas, lo que explicaría la donación a tributo de un casal que recibe Mahoma Maruan (1414) de Raimundo de Buil, y un campo en la partida de La Plana de Monteara que da a tributo el señor de Pisa (1447) a Mahoma Alfocén. Aparte de la compra en 1484 de un campo con un obrador y una casa que hace Jahe de Fornos alias Moreno, tenemos documentadas tres compras más: en 1485, Jahe Franco alias Cabero compra un campo por 65 sueldos al judío Sansón Açach: en 1513 Brahim Calvo alias Yçotas compra un campo en Tremosiellas a Mahoma de Pueyo alias Lacayo, quien se reserva el noveno del fruto; no pone el precio, lo que nos hace pensar que estamos también ante una donación a tributo más que ante una compra; por fin, en 1519 el rico Çalema Franco compra un campo franco en la Cuesta del

41.- En el repertorio toponímico oficial de la villa se comprueba que éste, aparte de los mencionados en las salinas, es el único topónimo medieval que ha sobrevivido de todos los que aparecen en el trabajo. Ver: .http://idearagon.aragon.es/toponimia/t22160.htm. 
Río, lindero con su demba ${ }^{42}$ a Mahoma Franco hijo del quondam (difunto) Azmen, por la considerable suma de 430 sueldos, y se da carta de gracia para poder recuperar el campo, lo que posiblemente dé a entender que más que una compraventa se trata de un préstamo con garantía, ya que el vendedor puede recuperar la tierra si devuelve el dinero.

Del resto de los campos registrados no sabemos ni la localización ni ninguna otra cosa salvo el nombre de su propietario y la fecha en que aparecen mencionados. Son los siguientes: Jucé lo Burro (1467, 1483, 1485), Muça lo Burro (1478), Jucé Zayton (1483), Brahim lo Burro (1483, 1485), Brahim de Calvo (1483, 1485), Eyça Ceyt (1484), Zora de Calvo (1484), Azmet de Franco (1484), Mahoma Cotón (1485), Mahoma Galbán (1485), Mahoma Mallor (1485), Jahe Alfocén (1485), Jucé Cerantón (1485), Brahim Franco menor (1486), Eyça del Royo (1501) y Mahoma Navarro (1503).

Como ha podido apreciarse, son muchos los moros poseedores de tierras de cultivo, lo que no quiere decir que en todos los casos estemos ante labradores; el hecho de que muchas de estas fincas las conozcamos porque sus propietarios las ponen como garantía en operaciones dinerarias, nos permite pensar que en muchos de los casos conocidos estemos ante gente que tiene en la agricultura una actividad complementaria a su negocio relacionado con el comercio y/o con la explotación de salinas.

\subsection{Las comandas}

Aparte de algunos documentos que recogen compraventas y otros aspectos de interés económico, que ya se han visto y otros se verán a lo largo del trabajo, el mayor número de escrituras que ahora interesa se refiere a comandas, firmadas en Barbastro y un buen número de ellas durante las ferias de agosto, cuando en la ciudad coincidían los moros de la comarca, que la visitaban frecuentemente para sus negocios, con otros procedentes de lugares aragoneses bastante alejados, como Calanda, y numerosos mercaderes y trajineros extranjeros, algunos relacionados con moros de Naval, como un navarro y varios gascones, que nos permitirán descubrir las redes comerciales de nuestros moros. Estas comandas, incluso las que se efectúan entre moros, se hacen según el Fuero, sin que en ningún caso parece que se aplicara la ley islámica ${ }^{43}$.

42.- La palabra aragonesa "demba" significa un campo próximo al pueblo o un pequeño campo junto a las eras aprovechado como henar.

43.- Ma José Roy Marín: "Las comandas-depósito entre las minorías religiosas en la Zaragoza medieval", Revista de Historia Zurita, 74, (1999), pp. 27-50. Recoge estudios anteriores sobre la comanda medieval y estudia el tema de la comanda en las comunidades zaragozanas judía y mora. Presenta 
La mayor parte de las comandas son de carácter comercial; otras son préstamos que para evitar las limitaciones que la ley imponía al interés de los mismo recurren a la forma legal de comanda, y a veces a la de "comanda puro depósito", posiblemente, por lo visto en la documentación de la aljama de Naval, pero también en las de Huesca y Barbastro, un tipo de comanda relacionado con acciones mercantiles. Alguna de ellas se ven canceladas, pero no todas. En total tenemos documentadas ciento tres comandas, cincuenta y ocho recibidas por moros y cuarenta y cuatro entregadas por moros, a cristianos o moros, más una en las que las dos partes son moros de Naval. Como se verá, las hay que mueven cantidades considerables de dinero, lo que coloca a algunos moros de Naval entre esa minoría de musulmanes dedicados al comercio, bien como mercaderes o simplemente trajineros, y también en la minoría más selecta de prestamistas.

La presencia de mujeres en estos documentos se reduce a la de Zora de Calvo, viuda, y sus hijos Jucé y Mahoma lo Burro, que ponen como garantía sus tierras. Reciben la considerable suma de 1080 sueldos de sus vecinos Mahoma Franco, Muçot lo Burro y Jucé Barrio (1484). Es ésta la única operación documentada entre moros de Naval y llama la atención la cantidad, excepcional en el marco local. No sabemos si se trata de una comanda préstamo, pero no aparece cancelada. Posiblemente estamos ante una comanda mercantil, la familia Burro parece de las más ricas de la comunidad y se hace difícil creer que tuvieran la necesidad de pedir un préstamos de esa magnitud. Un Jucé lo Burro es uno de los más activos en la década de 1460, como luego se verá, y es indiscutiblemente un mercader en el sentido más estricto de la palabra. Por supuesto, por el tiempo transcurrido, no parece que sea el homónimo que aparece en este documento, pero bien podría ser su padre.

\subsubsection{COMANDAS TOMADAS POR MOROS NAVALESES}

La primera cosa que hay que hacer notar es que el nombre de quienes toman una comanda suele repetirse con frecuencia y, en mi opinión, es porque estamos ante personas que se mueven entre Naval y Barbastro con frecuencia y sin duda para llevar a cabo acciones económicas, No sabemos, salvo rarísimas excepciones, qué transportaban, pero, trajineros o mercaderes, tenían

\footnotetext{
un panorama de la minoría mudéjar que estudios más recientes ponen en cuestión, tal como el empobrecimiento general y la idea de aljamas cerradas; hubo mudéjares ricos, especialmente en el marco urbano, y también en el mundo rural, como se ve en este trabajo, y dominaban las morerías abiertas, tanto en la ciudad como en el campo, como puede verse en Ä. Conte: La aljama de Huesca y La aljama de Barbastro.
} 
Barbastro como punto de encuentro con sus clientes o con sus abastecedores, y la frecuencia con que el mismo individuo aparece en la ciudad es una prueba de su relación con el mercado, que no se daba sólo durante el periodo ferial de agosto, sino durante todo el año.

Las cincuenta y ocho registradas van desde 1412 hasta 1521 , con una incidencia especial en las décadas de 1460 a 1480, que son los años de los que se tiene más documentación. De todas ellas, diez aparecen canceladas, y puede afirmarse que se trata de préstamos que al tomar la forma de comanda ocultan un interés por encima del legal, como ya se ha dicho. Hay tres casos clarísimos: uno de 1471, en el que Alí Galbán toma 220 sueldos de Domingo Sancho, que se compromete a devolver en tres tandas, aunque no hayamos encontrado los documentos de pago; otro caso es el de Eyça del Royo, que en 1498, en enero y mayo, toma sendas comandas; la primera de 155 sueldos del burgués barbastrense Jaime Panivino y que aparece cancelada siete años más tarde; la otra es también una comanda de tipo medio de 166 sueldos que toma del noble Juan de Alagón y que se da un plazo de diez años para que sea devuelta; obliga sus casas como garantía. Cuesta creer que en estos casos no haya interés oculto, resultan cuando menos extraños unos préstamos a tan largo plazo sin que hubiera un beneficio económico sustancioso para el prestamista. Las otras comandas en las que consta la cancelación son de cantidades muy variadas, pero todas ellas tienen en común que los receptores son más de uno, si exceptuamos la tomada del notable de Barbastro Juan de Santángel por Muça Jahe en 1460 (no sabemos de cuánto) y que aparece cancelada un año después.

En abril de 1467 se cancela la comanda que de la honorable Antona de Nava alias de Azlor habían tomado, exactamente dos años antes, por valor de 280 sueldos, Mahoma Dezmel, Hazmet de Franco, Brahim de Pueyo, Brahim de Serrato y Mahoma de Pueyo. Parece que en este caso estamos ante un préstamo por necesidad, como ocurre en 1468 cuando alguno de los anteriores, Mahoma de Pueyo, y Ovécar de Alfocén, Mahoma Almeller, Brahim Calvo, Mahoma Calvo, Mahoma Dezmel, Brahim Escudero y Brahim Franco reciben 400 sueldos de la misma prestamista; el hecho de que se tardara diecisiete años en cancelar la comanda reafirma la idea del préstamo oculto y, además, es un indicador de problemas económicos en los receptores. En ninguno de los casos anterior hemos sabido qué ofrecían como garantía, y lo mismo ocurre con la comanda de Jucé Taher y Mahoma Franco de 130 sueldos tomados en 1481 de alguien cuyo nombre resulta ilegible y que ya está cancelada cuatro meses después.

Años más tarde, en 1503, Mahoma y Brahim Calvo toman 320 sueldos del notario de Barbastro Sancho Castillón, cancelada a los diez meses. Por 
contra, sabemos que en 1478 Eyça Calvo, Jucé Jahe y Brahim de Franco obligan, respectivamente, un campo llamado O Güerto (El Huerto); dos eras salineras en El Ranero y dos eras salineras en La Rolda, muchos bienes para tan solo una comanda préstamo de 291 sueldos, cancelada ya a los catorce meses, concedida por Esperanza de Castro, la misma que en el mismo día entrega otra comanda, de la que no sabemos la cantidad, pero que sí fue cancelada al poco tiempo, a Brahim del Alamín — que por las fechas parece no ser el emigrado a Barbastro medio siglo antes-, y a Jahe Alfocén, Ovécar de Cotón, Brahim lo Burro y el judío Yçach Anbrón. Aún hay una nueva comanda de la misma dada en 1480 de 169 sueldos a Brahim Burro y a los cristianos de Naval Bernat de Latrero y García Calvo, cancelada cuatro años más tarde; como en otras ocasiones, los receptores renuncian a sus derechos y se someten a la justicia ordinaria. Aunque tal vez anecdótico, vale la pena tomar en consideración el dato de que moros y judíos actúen juntos.

Las abundantes comandas entregadas a más de una persona, y a veces a un número considerable, no parece que sea sino una triquiñuela legal para ahorrarse dinero en el coste de la escritura, al menos la documentación no da pistas para pensar que estemos ante individuos unidos en algún negocio. Bajar de Naval a Barbastro para ir al notario suponía ya tiempo y dinero, de modo que es comprensible la "alianza" de varias personas para, al menos, ahorrar gastos de notaría.Sobre todo, porque en la mayoría de estos casos estamos ante situaciones económicas severas, y aún más lo vemos en dos comandas de 1485 y una de 1500, de las que no consta la cancelación. En la primera fecha, Jahe de Alfocén, Mahoma Cotón y Muça Jahe, y los cristianos habitantes en la aldea de Lasosa de Naval, Benedet de Ezquerro y Juan Calvo, toman una comanda de tan solo 30 sueldos de Juan de Ejea por la que los moros obligan, respectivamente, dos eras salineras, un campo y una era salinera; realmente, una fortuna para tan poco dinero. Ejea, al que volveremos a ver actuando con moros de Naval, no sabemos qué oficio tiene, pero sí que debía de estar bien relacionado con la comunidad musulmana, ya que en 1475 es testigo en un documento del plenario de la aljama de Barbastro celebrado en el interior de la mezquita ${ }^{44}$. Inconcebible parece igualmente que Muça Jahe, también en 1485 , obligue cinco eras salineras por una comanda de la irrisoria cantidad de 10 sueldos que da el burgués Salvador de Santángel. Por mucha que fuera la necesidad, resulta del todo inexplicable que se pongan como garantía bienes cuyo valor multiplica por mucho el de la comanda. Más razonable, aunque también desproporcionada, es la garantía que pone Brahim Galtel por 88 sueldos que le encomienda el collidor general Exemén de Sampietro: tres 
eras salineras, cuyo valor, a tenor de lo que se paga por ellas, podría rondar los 900 sueldos. Una de las comandas préstamo que más años tarda en cancelarse es la de 256 sueldos que el señor de Ferreruelo cerca de Azlor, Ramón de Cáncer, da a Jahe Cotón, Ovécar Cotón, Mahoma Morillon y Moferriz de Alfocén, por la que obligan tierras y casas (1468); parece que esta deuda se salda nada menos que veinte años después, ya que queda documentado el pago que hacen los moros Mahoma Cotón, Jahe Alfocén alias Ferrachico y Eyça del Rey; es cierto que no coinciden los nombres, pero han pasado tantos años que la deuda ha podido pasar de padres a hijos o a otros parientes, de la misma manera que el señor de Ferreruelo ha cambiado y ahora es Juan de Cáncer. Excepcional, porque a un moro de Naval le acompaña uno de la villa mora de Enate, es la comanda de 48 sueldos que durante la feria de Barbastro de 1463 da Francés Benet, habitante de la ciudad, a Brahim Franco y Franco del Alfaquí, este de Enate, sin que conste con qué bienes avalan el préstamo que ya se ha saldado un año después.

Como se ve a lo largo del trabajo, ese año de 1485 da una documentación enorme y son numerosas las comandas llevadas a cabo, lo que podría hacernos pensar en momentos de dificultad para el colectivo o/y a una reactivación del comercio.

El otro grupo de comandas es el formado por las que parecen tener un carácter mercantil, y cuya cancelación no consta nunca. Las hay de muy diversa cuantía, desde unas decenas de sueldos a los mil. En todos los casos, parece que estamos ante depósitos de dinero como garantía de acciones mercantiles o un adelanto del producto contratado, sin que, lamentablemente, podamos saber de qué mercaderías se trataba.

Por debajo de los 100 sueldos son ocho y van de 1468 a 1501. Todas están protagonizadas por barbastrenses, salvo una de 1492 en la que Jahe Alfocén alias Ferrachico recibe como comanda depósito 53 sueldos de Pedro López, de Berbegal; el mismo Ferrachico tiene otra dos comandas, una en 1488 de 60 sueldos entregados por Nadal de Bielsa, y otra de 100 sueldos que ha tomado de Pedro Castillón (1494). En estas comandas obliga tierras y un asno. Es probable que estemos ante un trajinero que llevaba mercaderías entre Naval y Barbastro y viceversa, pequeños negocios a tenor del dinero que se mueve. Otro Jahe Alfocén al que no se le pone alias, tiene en 1485 comanda de 50 sueldos de Pedro de Santángel, familia ésta a la que vamos a ver actuar con frecuencia. Otro Ferrachico, Moferriz, tiene comanda de 88 sueldos y 1 dinero de Antón de Espluga en 1501, apellido que lleva un mercader, Antoni, en 1503. Comandas depósito son las que toman en 1468 Alí Galbán y en 1501 Eyça del Royo. La primera es de sólo 40 sueldos y los entrega Juan de Lecina; la segunda monta a 70 sueldos y es de Pedro de 
Cregenzán. Alí pone como garantía un campo con vides y Eyça, un campo y un mulo, posiblemente el medio que utilizaba para el transporte.

Las comandas entre 100 y 199 son bastante comunes y los nombres de los tomadores se repiten con frecuencia. Que sólo reciban una comanda de esta categoría están Jucé Zaytón (1483), quien toma 156 sueldos de Domingo Almallella, Bernat de Latrero y Miguel Lasierra; Jahe Alfocén menor recibe una comanda también depósito, como la anterior, de 120 sueldos de Juan Benet, se someten a Fuero y obliga unas eras salineras en El Pallero (1485); finalmente, Azmet lo Burro tiene 160 sueldos en comanda de Juan Abella alias Falcón por la que obliga su casa y una mula (1506). Cabe señalar aquí, que Juan Benet, como veremos, aparece en varias ocasiones como dador de comandas de tipo medio y alto; su relación con la comunidad musulmana parece frecuente, y así sabemos también que es procurador del moro de Huerto Jucé de Huerto (1470).

Cuando estamos ante comandas de carácter mercantil, el hecho de que sean dos o más los tomadores no necesariamente supone que lo hagan para ahorrar dinero en la escritura, sino que podemos intuir algún tipo de sociedad. Es el caso de Brahim Calvo y Brahim lo Burro, que los vemos recibir conjuntamente tres comandas, de 105 y 180 sueldos (1484) y un año después una de 135 sueldos. La primera es dada por Miguel Lasierra y obligan eras salineras; la segunda es de Salvador Santángel, y obligan mulos y tierra, y la tercera es del zaragozano Honorat Coll, y también se obligan tierras y salinas. Brahim Calvo recibe otra comanda de 166 sueldos (1485), en esta ocasión asociado a Jucé Cerantón y Jahe Alfocén, del zaragozano Honorato de Puzo, acaso el que antes ha aparecido como Coll; obligan tierras. Jahe Alfocén, uno de los personajes más activos en la vida de la aljama de Naval, recibe otra comanda, esta vez en solitario, en 1488 dada por Nadal de Bielsa por la que obliga un asno, animal de transporte mucho más que de labor.

Brahim Jahel tiene dos comandas, de 106 sueldos (1499) y 120 sueldos (1516); la primera dada por Domingo Lorent y Juan de Scapa y por la que obliga tres mulas, lo que nos demostraría su condición de trajinero o mercader; la segunda la concede Bernat de Mur y por ella obliga casas. Eyça Navarro, juntamente con Mahoma Cotón, reciben 102 sueldos (1458) de Antón de Burgasé; el mismo Burgasé vuelve a entregar 102 sueldos a Eyça Navarro en 1463. Esta repetición nos puede estar hablando de un mismo tipo de pedido comercial. En todos estos casos, el bien puesto como garantía son tierras en las partidas de La Lacuna y de La Rolda. Tres son las comandas entre 100 y 199 sueldos que quedan por ver. La primera, de 1464, la reciben Mahoma Galbán y Jucé lo Burro alias Canedo; son 100 sueldos que entrega Bertran de Marteror, labrador de Naval, aunque el documento se hace en Barbastro, en 
ella se obliga un mulo (1464). Jucé lo Burro recibe comanda de 114 sueldos de Nadal de Bielsa, a quien vemos actuar en más ocasiones con moros de Naval; Burro obliga campos (1483). Finalmente, en 1484, Brahim lo Burro recibe del moro barbastrense Camín Onzino, maestro de casas $^{45}, 130$ sueldos por los que obliga dos eras salineras; en el periodo ferial del mismo año, Burro recibe 180 sueldos de Salvador de Santángel, por los que obliga tierras y mulos, lo que nos manifiesta su buena posición económica: salinas, tierras y mulos.

Las comandas entre los 200 y los 399 sueldos pueden ser consideradas como de volumen medio y nos están hablando de negocios de una cierta envergadura al alcance sólo de individuos de buena posición económica o bien de grupos cuya relación interna nos es desconocida, No son extrañas las comandas tomadas por dos personas, así la de Jucé lo Burro y Alí del Rey, de 230 sueldos, que da Antón de Armengol, de Salas Altas (1464); la de Mahoma Calvo y Mahoma Morellón (1465) de 300 sueldos dada por Jaime Lospital y Pedro Santolaria, de Costean, y la de Jucé Burro menor y Brahim Burro, de 333 sueldos, del moro barbastrense Amet Oncino. En todos los casos, los bienes que se ponen como garantía son tierras de labor, mulos o casas.

Jahe Alfocén alias Ferrachico, del que ya hemos hablado, toma cuatro comandas de 270, 250, 268 y otra de 250 sueldos entre febrero y abril de 1485. En dos ocasiones se dice que obliga eras salineras y mulos. Las recibe, respectivamente, de Pascual Blanch, Martín de Montclús y dos de Ferrando Díez. La frecuencia de esas comandas nos está indicando una intensa actividad comercial por parte de Ferrachico. Otro Jahe Alfocén, en una ocasión llamado menor, toma tres comandas, dos en 1485 y otra en 1487, de 268, 270 y 238 sueldos respectivamente, la de 270 es juntamente con Brahim lo Burro. Son los dadores Martín de Montclús, Juan Benet y Antón Miranda. Mulos y eras salineras son los bienes que ponen como garantía. Montclús consta (1485) que había dado una comanda de 268 sueldos a Jucé de Alfocén alias Ferrachico en fecha indeterminada; la conocemos porque en la fecha indicada compra esa comanda Mahoma del Alamín, un tipo de inversión único en la documentación de moros de Naval pero muy frecuente en el momento. La repetición de nombres nos dice claramente que se trata de negociantes que solían mantener habitualmente tratos con los mismos clientes o abastecedores.

Cierran este grupo de comandas tres dadas a individuos en solitario. La más temprana es de 1412 y constituye uno de los primeros documentos que conocemos de los moros de Naval; en él, Jahel Muça tiene comanda de 13 
florines de oro, 8 sueldos y 2 dineros de un francés tintorero, Pes de Borau, residente en Canfranc, lo que pone en contacto puntos extremos en el norte de Aragón y no cabe duda, por el oficio, de que se trata de un mercader que comerciaba con telas. En 1512, Mahoma de Calvo tiene comanda de 212 sueldos de Miguel Fornillos, y en 1521 Alí Galino Gallo una de 330 sueldos de Juan Palacio del barrio de Santo Domingo, ambos dadores son cristianos de Barbastro, y solo esta última lleva la garantía de bienes obligados: casas y un macho.

Concluye este apartado con seis comandas que superan las 400 sueldos, de las cuales la más notable es la de 1000 sueldos que tiene Jucé Calvo juntamente con un cristiano de Aínsa que han tomado del ainsetano Bernardo de Ligüerre, posiblemente un comerciante; no sabemos cuándo se acordó, pero en 1413 se hace constar que no está pagada y que aún se debe esa cantidad, más que notable, lo que nos hace dudar si es un préstamo oculto o estamos ante una comanda de tipo mercantil. Dos comandas son tomadas por cuatro personas: en 1481 el clérigo de Barbastro Miguel de Moncley da comanda de 420 sueldos a Brahim lo Burro mayor, Jahe de Alfocén, Brahim Calvo y Jucé Reycon alias Royo que obligan campos en las partidas de Serrullye, Las Francas y Renaldo; la otra es de 1483 y en ella Juan de Ejea, al que ya hemos visto dar comanda a gente de Naval, da a Jahe Alfocén, Brahim lo Burro, Jucé lo Burro y Brahim Calvo la cantidad de 456 sueldos, obligando mulos y casas. Como puede observarse, de nuevo la repetición de nombres nos deja entrever relaciones comerciales habituales. Otras tres comandas tienen a dos individuos como protagonistas. En 1434 son Aça (Eyça?) Navarro y Alí Franco quienes firman una comanda de 400 sueldos de Juan de Amana en la que participa como testigo el rector de Pomar, Jayme Pomar, y el moro de Barbastro Brahim del Alamín, posiblemente inmigrado de Naval, como ya se vio. En 1445, Jucé Calvo y Mahoma Franco reciben en comanda 400 sueldos de Bertolomeu de Laseras, y en 1485 Jahe Alfocén mayor y Brahim Calvo la tienen de 445 sueldos del notario de Barbastro Joan Benet, y en este caso sí se ponen bienes como garantía: casas, campos y mulos.

\subsubsection{COMANDAS ENTREgAdAS POR MOROS}

Muchos de los nombres que hemos visto anteriormente, van a aparecer nuevamente en este apartado. En líneas generales, se puede decir que las comandas concedidas por los moros de Naval, que nunca aparecen canceladas, son de menor cuantía que las recibidas y que abarcan un marco geográfico mucho más amplio, de modo que los vamos a ver actuar mayo- 
ritariamente con gentes procedentes de puntos muy alejados que confluían en la ciudad del Vero, un centro comercial de primera línea en el panorama aragonés, y no sólo por sus ferias de verano. Nada sabemos con qué mercancía se trabajaba, salvo el caso ya citado de la entrega de una comanda de 10 quintales de "olio bello, limpio y mercadero" que hace Mahoma Franco a Dompingo Laspuertas, de Colungo, quien obliga un campo y un olivar (1485). De todas conocemos la cantidad entregada, si se exceptúa la que en 1521 da Mahoma de Ovécar al trajinero de Pamplona Martín Xullege, definida como "comanda puro fiel depósito", y, como en tantos otros casos, cabe la duda de si son puros préstamos o pago adelantado de una mercancía, especialmente porque son excepcionales los documentos notariales de Naval que en un estudio diplomático se ajustan a los modelos que vemos en el trabajo de Roy ${ }^{46}$, de ahí ciertas discrepancias que pueden aparecer entre su trabajo y lo que aquí se expone.

De entre las comandas entregadas por moros navaleses destaca por encima de todas la de 220 florines de oro que en 1412, durante las ferias de Barbastro, entrega Jahe de Naval a Alamén y Çalema de Albaho, de Huesca, que se habrá de pagar en dos tandas, por San Martín y por santa María de febrero. El dinero que mueve esta operación nos está hablando de un personaje de gran poder económico, muy lejos del tópico del moro pobre y marginal.

Las inferiores a 100 sueldos nos están reflejando pequeños negocios realizados con gentes de variada procedencia. Entre habitantes de Naval tenemos la que en 1414 da Ovécar del Ezcandar —apellido común entre los moros de Huesca y Barbastro- ${ }^{47}$; son 60 sueldos que reciben T. de Arcusa, Juan de Aguasca, el moro Sceit (Ceyt) y el judío Haym Avienply, quien lleva como testigo a su correligionario Açach Comperat. Una comanda de 7 florines de oro da Jahe Mofereg (1424) al bearnés Arnault de Castelbó, que es una prueba de la extensión de las redes comerciales de nuestros moros, como también la comanda dada al habitante de Canfranc Miguel de Larich por Eyça del Royo (1514), de 96 sueldos, y la de Çalema del Alamín al moro de Borja Amet Faraig (1506), de 96 sueldos. Otras se circunscriben a la comarca: Barbastro (1483), Mahoma de Franco da 50 sueldos a Gabriel de Santarromán; Cregenzán (1487), Eyça Calvo da 60 sueldos a Martín Perellón, posiblemente un agricultor porque obliga dos bueyes; y Salinas (1506), donde vive Pedro Robiella quien recibe 60 sueldos de Hamet del Alamín, con obligación de casas y una somera (burra).

46.- M. J. Roy: "Las comandas".

47.- Á. Conte: La aljama de Huesca, p. 50; La aljama de Barbastro, p. 281. 
La misma extensión geográfica podemos ver en las comandas que están entre los 100 y los 923 sueldos, como vamos a exponer a continuación, aunque antes vale la pena anotar la comanda depósito de 1400 sueldos que en febrero de 1476 dan Moçot lo Burro, alamín de la aljama de Naval, y Jucé Barrio a Andreu Verdeguer, de Barbastro, y que aparece cancelada en noviembre del mismo año. Esta acción no tiene nada que ver con el comercio, sino que está relacionada con el censal que a comienzos de año había vendido el concejo, incluidos moros y judíos, a Andreu Verdeguer, como ya se ha visto.

Agrupamos las comandas en esta ocasión por zonas geográficas, toda vez que eso nos ayudará a medir con más precisión el papel de los moros navaleses en el comercio de la comarca y de la zona pirenaica. Las relaciones internaciones, aparte del caso del navarro mencionado antes, se dan con gentes del sur de Francia y todo parece indicar que a través de los puertos de Canfranc y de Sallent, localidades en las que también hay enlaces. Todos los lugares se encuentran en un área pequeña, de modo que debía de haber algún tipo de relación entre todos ellos y el punto de encuentro con los moros era Barbastro y en ocasiones Huesca, por ejemplo el documento hecho en 1484 entre Eyça Ceyt y Miguel de Ramón, de la Val d'Osau, por el que el gascón recibe en comanda 240 sueldos. En 1468, Mahoma Alfocén da en comanda 100 sueldos al habitante de la villa de Nay Bernat del Abat 100 sueldos. De cerca de Nay, del lugar de Bordes (Borda en el documento) es Guillem de Benches alias Arremat, que tiene en comanda 180 sueldos de Mahoma Cabero (1507). Del Valle de Aspa tenemos tres documentos de 1500, protagonizados por Mahoma de Ovécar, Mahoma Çalema y Brahim Galtel, quienes dan, respectivamente, 200 sueldos a Gastón y Guillem Solach, del lugar de Borce (Buerça en el documento); 320 sueldos a Joan Donaguer, del lugar de Aydius, quien obliga dos mulos; y 220 sueldos a Antoni Latravendre y Guallar Porcet, cuyo lugar de residencia no consta, pero sí que son del Valle de Aspa. De la misma zona, de Bañeras de Luchon, es Petijoan de Banyeras del condado de Comenge, quien recibe 130 sueldos de Azmet Franco. De dos bearneses más desconocemos la zona de la que proceden, Pedro de Barraus (1487) y Joan Costas (1497), de quien se dice que es de Vides, que no he podido localizar; el primero recibe 200 sueldos de Jucé Morellón, y el segundo, 350 de Mahoma Morellón; ambos obligan mulas, como posibles trajineros o mercaderes.

En la vertiente aragonesa de los Pirineos, hay relación con gentes de Benasque (1491), Canfranc (1517) y, sobre todo, del Valle de Tena, en varios años. En Benasque, Mahoma Calvo da 100 sueldos a Sancho Lacasta, y en Canfranc Juan Nogués recibe una de 923 sueldos de Brahim lo Burro; en este caso, una cantidad realmente alta, estamos ante un negocio que multiplica el valor de todos los demás, de ahí que Nogués dé garantía con cuatro mulas. En 
el Valle de Tena, los dos puntos en los que encontramos enlaces son Sallent (1485 y 1522, éste documento hecho en periodo ferial de Barbastro) y Pueyo (1514 y 1515); las dos comandas de Sallent están protagonizadas por las mismas personas y son de la mima cantidad, 320 sueldos, quien las entrega es Jucé Franco hijo de Mahoma, difunto, y el receptor es Sancho Sánchez de Mozota. Es muy interesante ver que en un periodo tan largo de tiempo se mantienen los lazos económicos entre ambas personas y las condiciones, porque es la misma cantidad la que se pone en juego y los bienes como garantía son también dos mulas. Esto nos hace suponer que, a pesar de la falta de documentos que lo certifiquen, no es osado pensar que las relaciones de las que estamos hablando eran mucho más regulares de lo que parece. En Pueyo, también es el mismo moro quien protagoniza los documentos, Eyça del Royo. En 1515 sabemos que el receptor de 280 sueldos es Domingo de Lasclabes, que obliga un mulo. Los dos documentos de 1514, hechos ambos el mismo día de abril, tienen, como receptor, uno, a un tal Pascual, de Pueyo, y el segundo a un tensino (o un grupo) sin que sepamos el nombre, algo que impide el mal estado del documento, aunque sí sabemos que son 280 sueldos, la misma cantidad que vemos en la comanda tomada por Lasclabes en 1514, lo que invita a pensar que bien pudiera tratarse de la misma persona y de la misma operación que se repetiría un año después. Que no se trata de préstamo, sino de una operación mercantil lo abona el hecho de que en el caso de la comanda que hace a Pascual se adquiere el compromiso de hacer albarán cuando sea cancelada; estamos, en mi opinión, ante un pago adelantado de mercancías.

Comanda dadas en tierras de Aragón, aparte de las de la comarca de Barbastro y Huesca, tenemos una en el campo de Borja, en Ambel (1481), y siete en Calanda, lo que demuestra unas relaciones bastantes consolidadas con esta villa. En todos estos casos hay que hacer constar que los receptores son siempre moros, algo que parece indicar los vínculos que mantenían las diversas comunidades musulmanas del reino. En Ambel la encomienda la da Brahim Franco y los receptores son Mahoma y Brahim de Alura, quienes por sólo 130 sueldos obligan tres mulos, posiblemente los que utilizan para el transporte de las mercadurías. Son tres los moros de Naval que se relacionan con moros calandinos: Jahe de Furno (o Fornos) alias Moreno, Muçot lo Burro y Mahoma Çalema. Jahe de Furno alias Moreno da dos comandas en 1485, la primera de 240 sueldos en abril a Brahim Garabich, que obliga un mulo; la segunda, en periodo ferial de Barbastro de la misma cantidad a Brahim Gazubes, que no sería de extrañar que fuera los misma persona, teniendo en cuenta las mil maneras que tienen los escribanos cristianos de escribir el nombre de los moros. Esa repetición de comanda la vemos en el 
caso de Muçot lo Burro, quien en abril de 1485 entrega 120 sueldos a Alí Alfaquín y durante la feria repite la cantidad con la misma persona, que obliga bienes sin especificar. Como se ve, son muchos los casos en que coinciden ambas partes del negocio, y lo mismo vamos a ver con Mahoma Çalema, que en 1500 da comanda de 12 florines de oro a Alí Samperuelo y en 1516 los volvemos a encontrar en una comanda de 224 sueldos, con unos mulos como bienes obligados. La tercera comanda de Çalema en Calanda es en 1500 a Alí Marriol, de 200 sueldos.

En un ámbito geográfico más cercano a Naval, vemos a los moros actuar con gentes de Huesca, Casbas, Barbastro, Costean, Betorz, Guardia y Lecina. En Costean, las dos comandas son de 1472 y en ambas interviene Eyça lo Burro; en la primera da 210 sueldos a Bonet Palacio, a su hijo Jaime y Antonio Huaredia quienes obligan dos bueyes; en la otra, da 119 sueldos a Tomás de Buera y Jaime Palacio, el mismo del documento anterior; en la segunda, se pone un buey como garantía. El mismo Eyça lo Burro y en el mismo año, da un comanda de 110 sueldos a Bartolomé de Trillo, vecino de Guardia, aldea de Hoz de Barbastro. En Barbastro, intervienen Jahie de Fornos (1469), que da comanda de 100 sueldos al moro Mahoma de Axa; Jucé Franco, que en 1484 da 300 sueldos a Axa Franco, viuda de Mahoma Barrach, de Barbastro, y a su hermano Brahim Franco, y a los cuatro hijos de Axa, que pasan a estar tutelados por Brahim en Naval, y no por su madre en Barbastro ${ }^{48}$, ponen como garantía una tienda y casa en la ciudad; y, finalmente, Brahim lo Burro da comanda de 240 sueldos a Bernat Abadía, que obliga dos mulos. El mismo Jahe Fornos que hemos visto antes, actúa con Juan Nabarro (1465), de Casbas, al que da comanda de 270 sueldos por la que pone como garantía un mulo. En Betorz, concretamente en Santa María de la Nuez (Unz en el documento) Muçot y Jucé lo Burro dan 110 sueldos a Bertrán Saliellas (1474), que obliga una mula. Para acabar, queda la comanda de 160 sueldos que Jahe Farax y Mahoma Calvo dan a Domingo Sesé (1479), de Lecina, aunque en este caso estamos, con toda seguridad, ante una comanda préstamo, ya que aparece cancelada dos años más tarde. En Huesca, ya se ha citado la excepcional comanda de 220 florines de oro que entrega Jahe de Naval en 1412 a Alamén y Çalema de Albaho.

\subsection{Las procuraciones}

Aunque las que conocemos son escasas, es una fuente más para ahondar en la certeza de que algunos moros navaleses tenían redes comerciales que los 
ponían en relación con el comercio a corta y media distancia. Además, estas procuraciones manifiestan la convivencia entre moros y cristianos, toda vez que ser procurador de alguien supone gozar de toda su confianza, y vamos a ver cómo no son infrecuentes los documentos en que las partes tienen diferente religión. Moros procuradores son: Jucé de Alfocén, de Axa de Barbastro (1465); Jucé Canero, de Juan Sanvicente, de Aínsa (1471); Jahe Afocén del gascón tintorero habitante en Barbastro Arnalt de Casas, que en el mismo documento nombra procuradores a varios cristianos de su ciudad y de Tarbes (1488); Eyça el Royo lo es del mercader zaragozano Juan Spicenvert, que le autoriza a usar sus franquicias, lo que demuestra que Eyça era comerciante o trajinero (1514); y Mahoma Menescal, que es nombrado procurador junto a cristianos de Barbastro del moro de Zaragoza Alí Marco (1524).

Los procuradores nombrados por moros de Naval son Mahoma, de Pueyo de Cinca, y Adoy de Burgamán, de Ripol, (1467), ambos para tratar los asuntos económicos de Jucé Cavero y Muçot lo Burro, cuya actividad se extendía, como mínimo, por esos lugares; Juan de Cregenzán, Jucé Rey y Ayçotes Calvo, todos de Naval (1480) son procuradores de Jucé Barrio, y posiblemente estamos ante tres navaleses cuyo oficio era también el de trajinero; Domingo Alborán, de Naval, es procurador de Mahoma de Ovécar (1506) con la facultad de cobrar deudas, hacer albaranes y otras operaciones comerciales, lo que de nuevo nos pone ante un moro de Naval dedicado al comercio y con el poder suficiente para delegar en otros aspectos tan importantes como el cobro de deudas. A veces se recurre a personas de solvencia y, sobre todo, de prestigio como garantía de eficacia, es el caso de Mahoma lo Burro alias Purroy, Eyça Calvo y Moferriz Alfocén que nombran procurador para muchos asuntos (cobros, albaranes, representación en pleitos, etc.) al notario de Barbastro Sancho Castillón (1509), quien ya estaba relacionado con el colectivo moro de Naval, como lo demuestra la comanda, ya vista, que en 1503 había dado a Mahoma y Brahim Calvo. También el cobro de deudas, especialmente las del habitante de El Grado Bernat Esteban, es lo que lleva a Mahoma Galter a nombrar procurador a Gaspar Galino, de Barbastro. En 1519, Brahim lo Burro nombra nada menos que a cuatro moros de su pueblo y a un cristiano de Barbastro como procuradores para controlar sus deudas y negocios; cinco procuradores es un número muy grande y nos habla del potencial económico de Burro; son los procuradores Eyça Zeyton, Mahoma Moreno, Jucé lo Burro menor y Mahoma Rocon, y el cristiano Francisco de Fresa. Muy claro en cuanto a las funciones de procurador es el documento hecho por Alí Jahel (1522) en el que nombra procurador a Salvador Pano, de Barbastro, cuya función será la de hacer albaranes y cobrar deudas. 
Como se ve, no son muchos los documentos que caben en este apartado, pero ilustran perfectamente sobre las actividades mercantiles de los moros de Naval, sin que en ningún caso hayamos podido saber con qué comerciaban, aparte de aceite, ovejas, caballerías y hierro que sí está documentado, tal como se ha visto. No cabe duda de que algunos de estos moros pueden considerarse ricos, como algún caso ya visto, con inversiones muy notables, o la que en 1466 hacen Mahoma de Maestro y Mahoma Crespin, que compran por 1000 sueldos todos los bienes muebles, inmuebles y dinerarios de Mahoma de Axa en la ciudad de Barbastro. Disponer de ese dinero y además invertirlo en la ciudad indica no solo una buena posición económica de estos navaleses, sino su afán de hacerse, aunque lejos de su hogar, con bienes que con toda seguridad fueron explotados por terceros.

\subsection{Testigos}

Numerosos moros de Naval firman como testigos en documentos hechos en Barbastro por gentes de muy diversa procedencia. Es probable que en algunos casos el hecho se debiera, simplemente, a que coincidían en la notaría, pero no siempre es así, ya que en la fecha en que aparecen haciendo de testigos no hay certificado ningún documento protagonizado por ellos, por lo que habrá que buscar otras causas, y sin duda lo más creíble es pensar que entre quien hace el documento y quien testifica hay algún tipo de relación personal y, por supuesto, no puede descartarse una relación económica. No deja de chocar que muchos de las personas que eligen testigos navaleses sean herreros y trabajadores de metal en general. La lista podría ser interminable, por eso elegimos simplemente los que parecen más significativos, por el lugar de origen o residencia de los protagonistas o por su categoría social. En 1466 vemos firmar como testigo en un documento de Mahoma de Axa, mercader muy documentado en Barbastro, de gran prestigio social, al más que probable mercader, o como mínimo trajinero, Muçot lo Burro ${ }^{49}$. En otro documento del mismo Mahoma de Axa, firma en 1469 Brahim Calvo, a quien hemos visto que poseía un buen patrimonio y varias caballerías, de lo que se deduce su relación con el comercio. Un tal Jahie es testigo de un documento de los moros francos Çalema y Mahoma Almortí, de Huerto, lugar en el que hay una comunidad mora notable que mantiene relaciones familiares y económicas con sarracenos de Barbastro (1474) $)^{50}$. Mahoma de Banco es testigo en un documento del notable Mahoma de Sasa, potentado herrero de Barbastro, y de Antona de Mur alias de Palacio, de Aínsa (1479). En documentos de

49.- Á. Conte: La aljama de Barbastro, p. 193.

50.- Ibídem, pp. 76 y 84. 
Mahoma de Avintarí, también un notable herrero de la aljama barbastrense ${ }^{51}$, firman Mahoma Franco (1481) y Mahoma Calvo (1483).

El menescal de Naval Mahoma Burro es testigo en un documento del oscense Muza Grisén, que se encontraba en Barbastro (1485) y es de suponer que para alguna acción comercial, ya que es dudoso que se desplazara para llevar a cabo algún trabajo relacionado con su oficio cuando en Barbastro los había y además prestigiosos. De Mahoma y Audalla Avintarí de Barbastro,de cuya familia ya se ha citado algún miembro, es testigo Muçot lo Burro (1485), a quien también hemos visto ya firmar como testigo. Los moros de Huerto Brahim Alboraybe y Mahoma de Yça tienen como testigo al navalés Mahoma Calvo (1486). En un documento del plenario de la aljama de Barbastro y en otro de la habitante en esa ciudad Fátima Alhama, mujer del herrero Çalema Serrano, firma Alí de Mora (1498). En una comanda de Brahim Morrut, moro de Monzón, firma Ovécar Coroy (1465); en uno de Altarán de Modef, de Enate, Mahoma Franco, (1510), y en otro del infanzón Martín de Noballas, de Ejea (1522), en el que se intenta forzar la conversión de su esclavo negro Barqua Benaye, musulmán que se niega a aceptar el cristianismo a cambio de su libertad, firma como testigo Azmet lo Burro, que se encontraba en la ciudad, que en aquellos momentos celebraba su feria ${ }^{52}$. Este último ejemplo es muy significativo, porque el acto que recoge el documento es excepcional por el asunto que trata, porque quien lo protagoniza es un pequeño noble y porque junto al moro de Naval firma un miembro de la aristocracia burguesa, Luis de Santángel. Si personajes de esa categoría recurren a Azmet lo Burro es porque también él gozaba del prestigio necesario. El hecho de que el acto tenga lugar durante las ferias de agosto invita a pensar que Burro estaba en Barbastro para mercadear. En una de las comandas más extrañas de las estudiadas, dada en 1485 por Juan de Ejea a tres moros de Naval y dos cristianos de la aldea de Lasosa, y en la que por sólo 30 sueldos se obligan una cantidad de bienes muy considerable, firma como testigo, además de un cristiano, Alí Medín o Almedín, de una familia acomodada de Barbastro que nos da dos homónimos, uno herrero y el otro cantarero ${ }^{53}$.

Recopilando los lugares en los que los moros de Naval tienen relaciones económicas o personales, son estos:

Aínsa (1413 a 1479), Ambel (1481), Barbastro (1445 a 1521), Bearne (1424 a 1507), Benasque (1491), Berbegal (1492), Bestué (1459), Borja (1506), Calanda (1485 a 1516), Canfranc (1412 a 1517), Casbas (1465),

51.- Ibídem, p. 141.

52.- Á. ConTE: La aljama de Barbastro, p. 116.

53.- Ibídem, p. 140. 
Colungo (1485), Coscojuela de Fantova (1484), Costean (1465 a 1472), Cregenzán (1487), Ejea de los Caballeros (1522), El Grado (1515), Enate (1463, 1510), Ferreruelo/Azlor (1468 a 1488), Hoz (1584), Huerto (1474, 1476), Huesca (1412 a 1465), Guardia (1472), Lecina (1479), Monzón (1465), Naval (1464 a 1519), Pamplona (1521), Pueyo de Cinca (1467), Ripol (1467), Salas Altas (1464), Salinas (1482 a 1514), Santa María de la Nuez/Betorz (1474), Valle de Tena/Sallent/Pueyo (1485 a 1515) y Zaragoza (1485 a 1524).

\section{CONCLUSIONES}

La pequeña comunidad mora de Naval, que en el siglo XV suponía aproximadamente la mitad de la población del lugar, no difiere del resto de colectivos musulmanes en cuanto a su organización interna y goza de autonomía para algunos asuntos, como la compra de censales, que interesan a la totalidad del pueblo. Hasta finales del siglo XIV toda la villa, y consecuentemente sus habitantes musulmanes, estaban bajo el poder real, que legisló abundantemente sobre la villa especialmente por la importancia de sus salinas y el monopolio de venta en un vasto territorio que abarcaba casi la totalidad de la actual provincia de Huesca. Cuando la villa pasó a manos privadas, continuó el control real sobre la sal y su comercialización a lo largo del tiempo que abarca este trabajo. Los moros mantuvieron eras salineras de manera general en plena propiedad, si bien sabemos de algunas que pertenecían a instituciones religiosas.

Otra actividad económica notable era la agricultura. Y mayor importancia parece tener el oficio de trajinero y de comerciante, con una red que se extendía hasta Canfranc, Sallent y tierras del Bearne por el norte y hasta Calanda por el sur. Lo que transportaban esos arrieros y lo que vendían estos comerciantes y mercaderes es una incógnita, salvo el aceite, objetos metálicos y lo que parece obvio, la sal, y hay datos que indican también relación con tintoreros y acaso comerciantes de paños.

Las operaciones dinerarias que proporcionan abundante documentación son casi exclusivamente comandas que no siempre parecen préstamos, sino que en ocasiones parecen pago por adelantado, una señal, para el intercambio de mercancía en ambas direcciones, de moros a cristianos y de cristianos a moros, sin que falten las que se dan también entre musulmanes.

A pesar de una cierta prosperidad, tanto la villa como la aljama se endeudan con cierta frecuencia con la compra de censales que no siempre aparecen cancelados. 
En cuanto al tema demográfico, la documentación estudiada nos permite conocer que la población mora de Naval superaba el número de fuegos que da el fogaje de 1495, que son veintiocho. Es lo único a lo que se ha llegado con certeza, y también a la existencia de movimientos de población entre las poblaciones vecinas con habitantes moros - Salinas y Enate - y la ciudad de Barbastro.

Por otro lado, los vínculos familiares y sociales entre los moros de la comarca parecen muy intensos, como lo demuestra la repetición de apellidos, la frecuencia en la que figuran como testigos en documentos de sus vecinos $o$ en las procuraciones que dan.

Todo parece indicar que la morería de la villa de Navalera abierta y que judíos, moros y cristianos convivían en una aparente armonía y compartían espacio.

Una minoría de esos moros de Naval se relacionaba con gente de buena posición social y económica de Barbastro, moros, cristianos o judeoconversos, y lleva a cabo acciones dinerarias de consideración, de modo que una vez más se rompe el tópico del moro acosado, reducido a un espacio urbano delimitado y empobrecido.

\section{Relacion alFabÉtica de MOROS DE NAVAl y FECHA EN LA QUE APARECEN CITADOS, SI ESTÁN DOCUMENTADOS EN VARIOS AÑOS SE DA EL PRIMERO Y EL ÚLTIMO}

(Se han unificado nombres y apellidos que en los documentos aparecen escritos de maneras muy diferentes)

Alamín, Amet o Hamet del $(1506,1511)$

Alamín, Brahim del (1478)

Alamín, Calema del $(1485,1511)$

Alamín, Mahoma del (1485)

Alborayna, Brahim de (1463)

Alcayde, Calema (1521)

Alcolea, Eyça de $(1483,1501)$

Alfocén, Amet o Hazmet (1481, 1483)

Alfocén, Jahe alias Ferrachico (1485, 1498)

Alfocén, Jahe mayor $(1475,1488)$

Alfocén, Jahe menor $(1478,1485)$

Alfocén, Jucé $(1465,1481)$
Alfocén, Mahoma $(1447,1487)$

Alfocén, Moferriz $(1460,1511)$

Alfocén, Ovécar $(1468,1485)$

Almadich, Alí (1506)

Almalech, Mahoma (1478)

Almeler (Almeller), Mahoma (1468, 1483)

Almeler (Almeller), Ovécar (1476)

Azmetu, Mahoma (1465)

Banco, Mahoma del (1479)

Barrach Franco, Brahimico $(1484,1485)$

Barrach Franco, Zora $(1484,1485)$

Barrach Franco, Gaya (1484) 
Barrach Franco, Mahoma (1484, 1485)

Barrio, Alí del (1511)

Barrio, Brahim del alias Cabero (1511)

Barrio, Jahe del alias Cabero (1485)

Barrio, Brahim del (1511)

Barrio, Jucé del (1476, 1484)

Barrio, Jucé alias Cabero (1476, 1485)

Benganzin, Mahoma (1515)

Burro, Azmet lo (1506, 1522)

Burro, Brahim lo hijo de Muçot (1515)

Burro, Brahim lo mayor $(1481,1511)$

Burrro, Brahim lo alias Adicha (1517, 1519)

Burro, Brahim lo menor (1511)

Burrro, Brahim lo $(1478,1515)$

Burro, Ceyt lo (1478, 1485)

Burro, Eyça $(1472,1485)$

Burro, Jucé lo mayor $(1478,1485)$

Burro, Jucé lo menor $(1484,1519)$

Burro, Jucé lo alias Canero (1464)

Burro, Jucé lo hijo de Zora de Calvo (1484)

Burrro, Jucé lo (1464, 1485)

Burro, Mahoma lo menescal de Naval (1485)

Burro, Mahoma lo hijo de Zora de Calvo (1484)

Burro, Mahoma lo alias Purroy (1509)

Burro, Mahoma lo $(1465,1484)$

Burro, Muça lo (1478)

Burro, Muçot (o Moçot) lo (1474, 1485)

Cabero, Jucé (1485)

Çalema, Mahoma $(1500,1516)$

Calvo, Brahim (1468, 1485)

Calvo, Brahim (1500, 1515)

Calvo, Brahim alias Yçotas (1513)

Calvo, Brahim mayor (1485)

Calvo, Eyça $(1478,1509)$

Calvo, Jucé (1445)

Calvo, Jucé menor $(1478,1498)$
Calvo, Mahoma (1465, 1500)

Calvo Mahoma alias Moreno (1516)

Calvo, Mahoma alias Muçenico (1513)

Calvo, Ovécar (1515)

Calvo, Zora de (1484)

Canero, Jucé $(1471,1484)$

Çapatero, Jucé (1501)

Cavero, Jucé (1467, 1483)

Cerantón, Jucé (1485)

Cernico, Mahoma (1468)

Ceyt, Alí de (1468)

Ceyt, Eyça (1468, 1484)

Ceyt, Eyça alias Galino $(1515,1519)$

Ceyt, Jucé (1481, 1485)

Ceyt, Mahoma de (1511)

Coroy, Ovécar (1465)

Cotón, Jahel (o Jahie), (1485, 1511)

Cotón, Amet (1485)

Cotón, Mahoma (1458, 1488)

Cotón, Mahoma (1515)

Cotón, Moferriz (1511)

Cotón, Ovécar (1468, 1484)

Crespin, Mahoma (1466)

Cubero, Jucé (1485)

Darle, Jahe (1485)

Dezmel, Mahoma $(1465,1468)$

Dosmen (Dezmel?), Mahoma (1478)

Doz, Mahoma (1468)

Escudero, Brahim (1468)

Ezcandar, Ovécar (1414)

Farax, Jahe (1479)

Ferrachico, Monferriz (1501)

Ferrero, Mahoma (1511)

Forner, Jahe (1488)

Fornos, Jahe (o Jahie) $(1465,1485)$

Fornos, Jahe alias Moreno $(1484,1485)$

Franco, Axa (1484)

Franco, Azmen, difunto, padre de Mahoma (1519) 
Franco, Azmet (o Amet) $(1476,1506)$

Franco, Brahim (1468, 1511)

Franco Brahim alias Doyde (1509)

Franco, Brahim mayor (1478)

Franco, Brahim menor (1486)

Franco, Brahim alias Lacayo (1513))

Franco, Çalema (1447)

Franco (Franquí), Çalema $(1511,1519)$

Franco, Hazmet (1465)

Franco, Jucé (1479, 1486)

Franco, Jucé hijo del difunto Mahoma (1485)

Franco, Jucé (1522)

Franco, Mahoma (1411)

Franco, Mahoma (1473, 1510)

Franco, Mahoma mayor (1519)

Franco, Mahoma menor (1485)

Franco, Mahoma menor $(1511,1516)$

Franco, Mahoma hijo del difunto Azmen

Franco, Mahoma hijo de Mahoma

Franco, Osinen (Osama?) (1478)

Furno, Jahe alias Moreno (1485)

Galbán, Alí (1468, 1478)

Galbán, Jahe (1483, 1511)

Galbán, Mahoma (1485, 1511)

Galino (1521)

Galino Gallo, Alí (1521)

Galtel (Galter), Brahim (1500)

Galtel (Galter), Mahoma (1511, 1515)

Gaycho, Ovécar de (1476)

Jahe (Jafe), Jucé (1478, 1485)

Jahe, Mahoma (1501)

Jahe, Mahoma menor (1485)

Jahe, Muça (1485)

Jahe, Muçot (1484)

Jahe (Jahel), Brahim (1499, 1516)

Jahel, Alí (1522)

Jahel, Mahoma (1511)

Jahel, Muça (1412)
Jahe, Muça $(1476,1478)$

Jahie (1474)

Lacabeza, Jucé hijo de Mahoma (1515)

Maestro, Mahoma del (1466)

Mallor, Mahoma (1468, 1485)

Manco, Mahoma el (1465)

Maruan, Mahoma (1414)

Mayo, Mahoma (1476, 1485)

Mellon, Mahoma (1483)

Menescal, Mahoma (1419, 1524)

Minyana, Muça (1403)

Mofereg, Jahe (1424)

Mora, Alí de (1498)

Morallon (Morellon), Jucé (1487)

Morallon (Morellon), Mahoma (1465, 1497)

Moreno, Jucé (1468)

Moreno, Mahoma (1485, 1519)

Muça, Jahe (1460)

Muça, Ovécar (1515)

Muçot, Jucé (1468)

Naval, Jahe de $(1412,1424)$

Navarro, Aça (Eyça) $(1434,1463))$

Navarro, Alí (1434)

Navarro, Eyça ( 1511)

Navarro, Mahoma (1483)

Ovécar, Ferrachico (1506)

Ovécar, Mahoma de (1500, 1521)

Pasavallas, Mahoma (1484, 1511)

Pueyo (Pueo), Brahim de (1478)

Pueyo (Pueo) Jucé (1517)

Pueyo (Pueo), Brahim de (1465, 1485)

Pueyo (Pueo), Mahoma (1465, 1485)

Pueyo, Mahoma hijo de Mahoma alias Chollo (1413)

Rey, Alí de (1464)

Rey, Eyça del (1472, 1488)

Rey, Jucé de (1480)

Reycon, Jucé alias el Royo (1481) 
Rocon, Mahoma (1519)

Rocon, Ovécar (1519)

Royo, Eyça del (1498, 1516)

Sansón, Eyça (1516)

Sasa, Mahoma (1482)
Sceit (Ceyt) (1414)

Serrato, Brahim (1465)

Tahe (Taher), Jucé $(1465,1481)$

Verdugo, Mahoma (1484)

Zayton, Jucé (1483)

\section{RELACIÓN DE FUENTES CONSULTADAS}

Archivo Histórico Provincial de Huesca (AHPH), Archivo Municipal de Barbastro (AMB), Archivo Diocesano de Barbastro (ADB), Archivo de la Corona de Aragón (ACA), Archivo Histórico Provincial de Zaragoza (AHPZ)

1403: AHPH, Pr. 3114

1411: AMB, Pr. Caja 1, Fatás 1411

1412: AMB, Pr. Caja 1, Fatás 1412

1413: AMB: Pr. Caja 1, Fatás 1413

1414: AMB, Pr. Caja 1, anónimo

1424: AMB, Pr. Caja 1, Fatás 1424

1434. AHPH, Pr. 3133

1445: AMB, A-400-001

1447: AMB, Caja D-2, 28

1458: AHPH, Pr. 4304

1459: AMB, Pr. Caja 7 Cenedo 1459

1460: AMB, Pr. Caja Cenedo 1460

1463: AMB, Pr. Caja 9, Benet 1463

1464: AMB, Pr. Caja 8, Cenedo 1464

1464: AHPH, Pr. 4306

1465: AHPH, Pr. 3153

1465: AMB, Pr. Caja 13, Abiego 1465

1466: AHPH, Pr. 3154

1466: AMB, Pr. Caja 9, Benet 1466

1467: AMB, Pr. Caja 16, Lunel 1467

1467: AMB, Pr. Caja 9, Benet 1467

1468: AHPH, Pr. 3156

1468: AMB, Pr. Caja15, Cervellón 1468

1468: AMB, Pr. Caja 16, Lunel 1468

1468: AHPH, Pr. 3157

1469: AHPH, Pr. 4311
1469: AMB, Pr. Caja 9, Benet, 1469

1471: AHPH, Pr. 3174

1471: AMB, Pr. Caja 18, Sin 1471

1472: AMB, Pr. Caja 18, Sin 1472

1472:AMB, Pr. Caja 14, Abiego 1472(2)

1472: AMB, Pr. Caja 18, Sin 1472

1473: AMB, Pr. Caja 16, Lunel 1473

1474: AHPH, Pr. 3162

1476: AMB, Pr. Caja 10, Benet 1476

1476: AMB, Pr. Caja 19, Sin 1476

1478: AHPH, Pr. 3577

1478: AHPH, Pr. 3166

1478: AHPH, Pr. 3177

1479: AMB, Pr. Caja 19, Sin 1479

1479: AMB, Pr. Caja 17, Lunel 1479

1479: AMB, Caja 14, Abiego 1479

1480: AMB, Pr. Caja 10, Benet 1480

1480: AMB, Pr. Caja 19, Sin 1480

1481: AMB, Pr. Caja 19, Sin 1481

1481: AMB, Pr. Caja 11, Asín, 1481

1481: AMB, Pr. Caja 17, Lunel, 1481

1481: AMB, Pr. Caja 10, Benet 1481

1481: AHPH, Pr. 3168

1482: AMB, Pr. Caja 17, Lunel 1482

1483: AMB, Pr. Caja 10, Benet 1483

1483: AMB, Pr. Caja 19, Sin 1483 
1484: AHPH, Pr. 3169

1484: AHPH, Pr. 3184

1484: AMB: Pr., Caja 17, Lunel 1484

1484: AHPH, Pr. 3184

1484: AMB, Pr. Caja 19, Sin 1484

1485: AMB, Pr. Caja 19, Sin 1485

1485: AMB, Pr. Caja 18, Lunel 1485

1485: AMB, Pr. Caja 11, Asín 1485

1485: AHPH, Pr. 3170

1485: AHPH, Pr. 3184

1485: AHPH, Pr. 3193

1485: AHPH, Pr. 4333

1486: AHPH, Pr. 3185

1486: AHPH, Pr. 3171

1486: AHPH, Pr. 4333

1487: AMB, Pr. Caja 20, Sin 1487

1487: AHPZ, Archivo Ducal de Híjar, 3/1-

31-52

1487: AMB, Pr. Caja 11, Asín 1487

1488: AMB, Pr. Caja 20, Sin 1488

1488: AHPH, Pr. 3172

1491: ACA, D/V 31-4

1492: ACA, D/V 31-4

1494: AMB, Pr. Caja 15, Cervellón 1494

1497: AMB, Pr. Caja 23, Abiego 1497

1498: AMB, Pr. Caja 22, del Grado 1498

1498: AMB, Pr. Caja 25, de Toledo 1498

1500: AHPH, Pr. 3251

1500: AMB, Pr. Caja 25, de Toledo 1500

1500: AMB, Pr. Caja 23, Abiego 1500

1501: AHPH, Pr. 3199
1501: AMB, Pr. Caja 25, de Toledo 1501

1503: AHPH, Pr. 3228

1506: AHPH, Pr. 3204

1506: AMB, Pr. Caja 24, Abiego 1506

1507: AHPH, Pr. 3254

1509: AHPH, Pr. 3255

1510: AHPH, Pr. 3208

1511: AMB, Pr. Caja 27, de Toledo 15111512

1512: AHPH, Pr. 3256

1513: AMB, Pr. Caja 27, de Toledo 15131514

1514: AHPH, Pr. 3252

1514: AMB, Pr. Caja 27, de Toledo 15131514

1515: AHPH, Pr. 3252

1515: AHPH, Pr. 3257

1516: AHPH, Pr. 3258

1516: AHPH, Pr. 3313

1516: AMB, Pr. Caja 31, Baltasar 1516

1517: AHPH, Pr. 3177

1517: AHPH, Pr. 3259

1519: AHPH, Pr. 3260

1521: AHPH, Pr. 3318

1521: AMB, Pr. Caja 25, Abiego 1521

1522: AHPH, Pr. 3262

1522: AMB, Pr. Caja 28, de Toledo 1522 1522: AMB, A400-002

1524: AMB, Pr. Caja 26, Giménez 1524

1624: ADB, Bastardelo de Visitas iniciado en este año. Legajo 577.

\section{BIBLIOGRAFÍA}

Directamente relacionada con Naval

$M^{\text {a }}$ Isabel Álvaro Zamora: "La ollería de Naval (Huesca)", Argensola, XVIII, no 71-72, (1977), pp. 71-94.

Privato Cajal Sazatornil: Cajal: X siglos de historia de Naval (Huesca) y sus salinas y anecdotario del autor, Barcelona, edición del autor, 1969. 
Ricardo Del Arco y Garay: "De la Edad Media en el Alto Aragón: I. Documentos de Alquézar. II. Privilegio de ingenuidad y franquicias de la villa de Naval. III. Cuaderno de privilegios reales de la villa de Sariñena. IV. Ordinaciones reales de Barbastro (1454)", Estudios de la Edad Media de la Corona de Aragón, II (1946), pp. 433-468.

J. Miguel Rodríguez Gómez: "La sal y el origen de la arriería (II): Naval, centro salinero del Alto Aragón (I)", Revista Serrablo, XXXVIII, $n^{\circ}$ 148, Sabiñánigo (junio 2008). Accesible en: http://www.serrablo.org/ revista/148/arrieros-en-serrablo.

Idem: "La sal y el origen de la arriería (III): Naval, centro salinero del Alto Aragón (II)”, Revista Serrablo, XXXIX, nº 152, Sabiñánigo (junio 2009). Accesible en:http://www.serrablo.org/revista/152/arrieros-en-serrablo.

Con algún dato de interés o relacionado con Naval

M.I. Álvaro, G. Borrás, E. SARAsa: Los mudéjares en Aragón, Zaragoza, CAI, 2003.

Asunción Blasco Martínez: "Notarios Mudéjares de Aragón (siglos XIV y XV), Aragón en la Edad Media, 10-11 (1993), pp. 109-134.

José Cabezudo Astrain: "Los moros de Barbastro y la cuestión de la mezquita", Miscelánea de Estudios Árabes y Hebraicos, XI (1962), pp. 115-120.

Ánchel Conte Cazcarro: La aljama de moros de Huesca, Huesca, Instituto de Estudios Altoaragoneses, 1996.

Idem: La aljama de moros de Barbastro, Barbastro, edición del autor, Barbastro, 2013.

Antonio Durán Gudiol: Colección Diplomática de la catedral de Huesca, 1, Zaragoza, Escuela de Estudios Medievales, 1965.

María Teresa Ferrer i MALlol: "Las comunidades mudéjares de la Corona de Aragón en el siglo XV: La población", VIII Simposio Internacional sobre Mudejarismo, Teruel, 1999, pp. 27-153.

Maria Luisa Ledesma Rubio: Estudios sobre los mudéjares en Aragón, Teruel, Centro de Estudios Mudéjares, 1996.

Germán NAVArro EsPinach: "Conquista cristiana y feudalismo: las tierras del Somontano en la Edad Media", en Comarca de Somontano de Barbastro, Colección Territorio. Portal de las Comarcas de Aragón, Zaragoza, Gobierno de Aragón, pp. 87-100. Accesible en: http://www.comarcas.es/ pub/documentos/documentos_II-4_33ca2948.pdf, 2006. 
Jaume Riera I SANS: "Los pastorells en Barbastro (julio de 1320)" en Aragón en la Edad Media, 18 (2004), pp. 299-336.

M José Roy Marín: "Las comandas-depósito entre las minorías religiosas en la Zaragoza medieval", Revista de Historia Zurita, 74 (1999), pp. 27-50. Antonio Serrano Montalvo: La población de Aragón según el fogaje de 1495, 2 vols, Zaragoza, Institución Fernando el Católico, 1995. 
